\title{
Hiding Information using Replacement in Silent Mutation of DNA Sequences
}

\author{
Sadoon H. Abdullah \\ sadosb113@uomosul.edu.iq \\ College of Science \\ University of Mosul, Mosul, Iraq
}

Received on: 12/09/2011

\author{
Ahmed S. Nori \\ ahmed.s.nori@uomosul.edu.iq \\ College of Computer Science and Mathematics \\ University of Mosul, Mosul, Iraq \\ Accepted on: 14/12/2011
}

The present study included an application of new method of steganography using DNA sequence as a media for hiding. This method is considered a secret cover for the secret message (text, image), avoid attention of unauthorized person in addition to be inextricable since it needs high effort, long time and well background in biology.

Hiding secret message in a known DNA sequence belongs to prokaryotic organism was conducted. The DNA sequence obtained from EBI location (European Bioinformatics Institute). Among the DNA molecule characters, one of the mutant ability types, that is the silent mutant, was choose to hide a secret message within the sequence. Then the sequence with the hidden message was sent to receiver via many methods.

For more precaution the DNA sequence with the message was hide as a colored image with different dimensions and extension (BMP, PNG). However, image quality remain unchanged. Results of study revealed high hiding ratio.

Keywords: Steganography, DNA Sequence, Silent Mutant, BMP, PNG.

$$
\begin{aligned}
& \text { إخفاء المعلومات باستخذام الاستبدال في الطفرة الصامتة لتسلسلات DNA } \\
& \text { أحمد سامي نوري } \\
& \text { كلية علوم الحاسوب والرياضيات }
\end{aligned}
$$

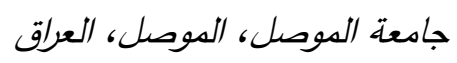

$$
\begin{aligned}
& \text { تاريخ قبول البحث: 2011/12/14 }
\end{aligned}
$$

\section{الملخص}

يهدف البحث إلى تطبيق طريقة حديثة في الإخفاء Steganography وذلك باستخدام سلسلة DNA

وسطاً لهذا الإخفاء إذ تعد غطاءً آمناً للرسالة السرية المخفية (نصية أو صورية) (Deoxyribonucleic Acid) ويتجنب إثارة انتباه الأثخاص غير المخولين وصعوبة استرجاعها من قبلهم لأنها تحتاج إلى جهد عالٍ ووقت طويلين ومعرفة تامة بعلم الأحياء.

تم العمل على إخفاء رسالة سرية ضمن سلسلة DNA لكائن بدائي النواة معروفة التسلسل أخذت من

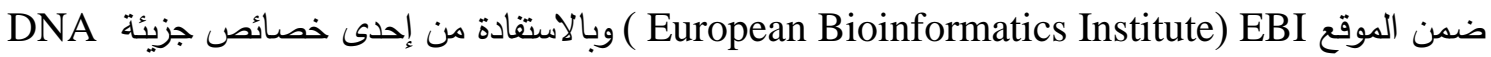
وهي الطفرة التي تكون من نوع الطفرة الصامتة تم إرسال السلسلة الحاملة للرسالة السرية إلى المستلم بعدة طرائق،

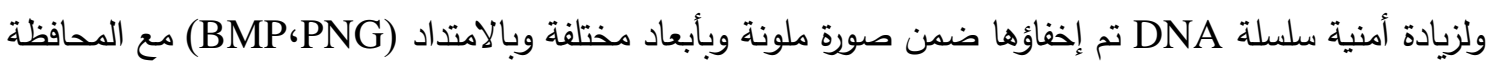
على جودة الصورة، إذ وصلت نسبة الإخفاء في هذا البحث إلى درجات عالية جداً.

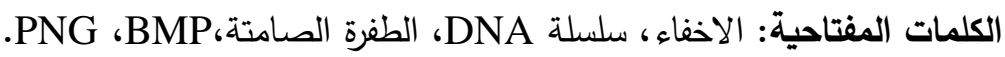


إن كثيراً من الحكومات وضعت قوانين تحد من استخدام طرائق التشفير أو منعها بصورة عامة [1][2]؛ لذا توجهت أنظار الكثيرين نحو استخدام تقنية (الكتابة المغطاة) للحفاظ على أمنية المعلومات المتبادلة بين طرفين،

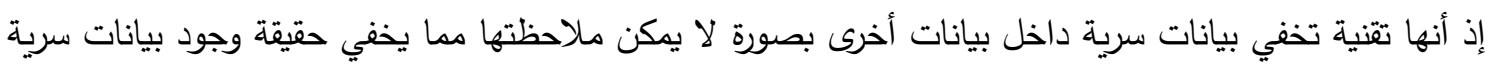

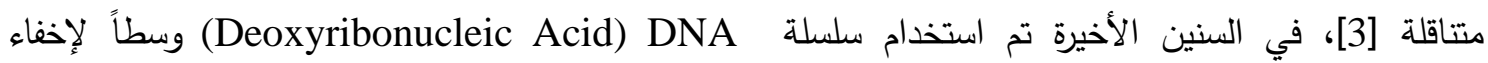
المعلومات السرية لما تتمتع به من مميزات[4]، خلال هذا البحث تم الاستفادة من خاصية الطفرة الصامتة لإخفاء

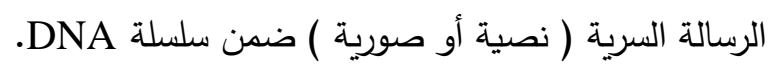
1- الخلفية النظرية في إخفاء المعلومات يُعرَّف إخفاء المعلومات على أنه عملية تضمين بيانات سرية في أشكال مختلفة من الوسائط منها الوسائط المتعددة الرقمية (Digital Multimedia) كملفات النصوص والصور والملفات الصوتية والفيديوية [5].وتُصنَّف تقنيات إخفاء المعلومات إلى تقنيات فرعية طبقا للورشة الدولية الأولى في إخفاء المعلومات [6][7] إلى :

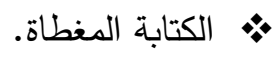

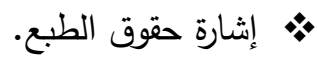

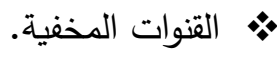

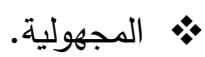

DNA الخلفية النظرية في الأحماض النوويـة الخلية الحية تعرف على إنها أصغر وحدة حية معروفة، وعادة ما تكون هذه الوحدات الصغيرة مكونة لأجسام الأحياء متعددة الخلايا (Multi cellular) مثل الإنسان والحيوان والنبات. وتتقدم خلايا الكائنات الحية من حيث التركيب الداخلي إلى قسمين هي خلايا حقيقة النواة (Eukaryote ) وخلايا بدائية النواة (Prokaryote).

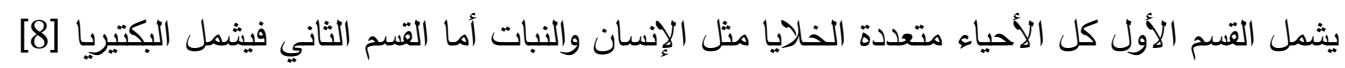
DNA 2-2 تركيب الحامض النووي الحامض النووي DNA ذو طبيعـة تسمح لـه بحمل المعلومات الوراثية بالإضـافة إلى إمكانيـة مضـاعفة

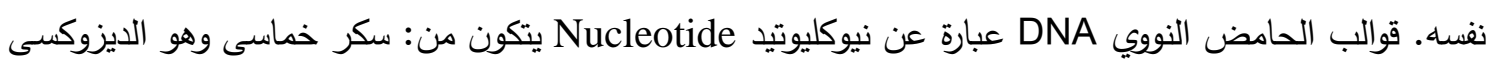

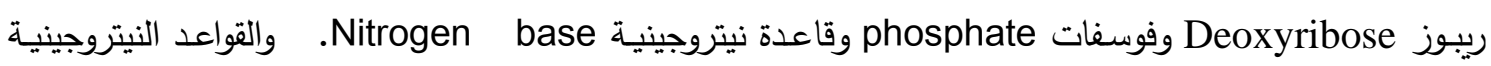

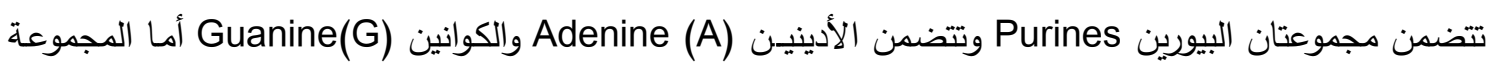

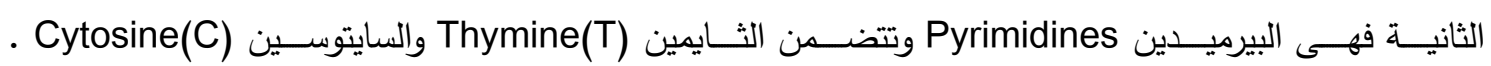
والنيوكليوتيدات ترتبط ببعضها بواسطة روابط لتكون سلسلة DNA [8] ـ كما في الثكل(1) 2-2 هناك نوعان من الأحماض النووية [8] :

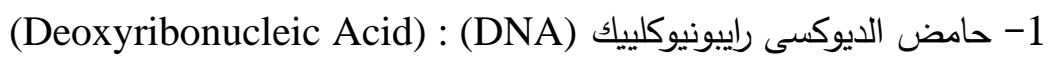
2- حامض الرايبرنيوكلييك (RNA) : (Ribonucleic Acid). 


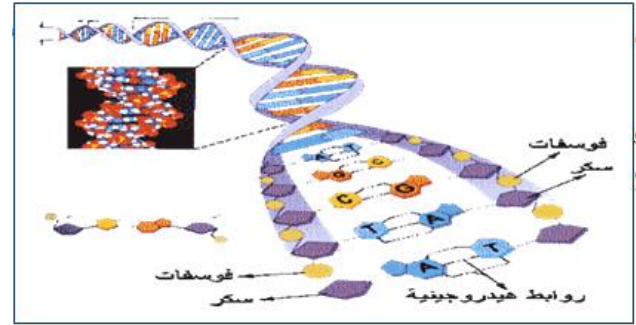

شكل (1). تركيب الحامض النووي DNA

ويشمل RNA بدوره على ثلاث أنواع من (RNA) جميعها تساعد (DNA) في القيام بوظيفته وهي:

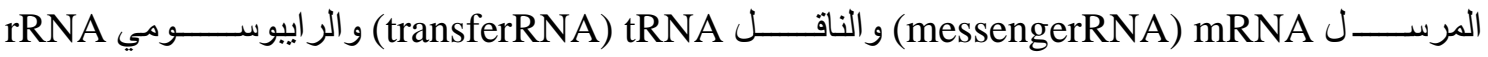
.(ribosomalRNA)

إن العمليات الرئيسية التي تحدث داخل الخلية والتي تكوّن سلسلة DNA المسؤولة عنها: 1- الاستنساخ والتضاعف. 2- 2 - الفصل أو القطع.

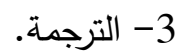

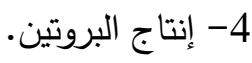

(الصبغيات) (3-2

تتنقل الصفات الوراثية من الاباء إلى الأبناء على شكل أجسام صغيرة جداً (كالعصي القصيرة) تسىى

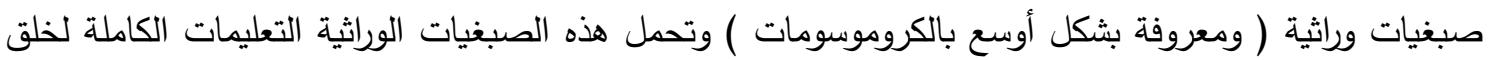
الإنسان. عدد الصبغيات (كروموسومات) الوراثية في كل خلية 46 صبغة (كروموسوم) وهي عبارة عن 23 زوجاً كل منها عبارة عن كروموسومين متثابهين بثكل كبير (وقد نقول تجاوزا إنهما متطابقان) وإحدى من هذهونه

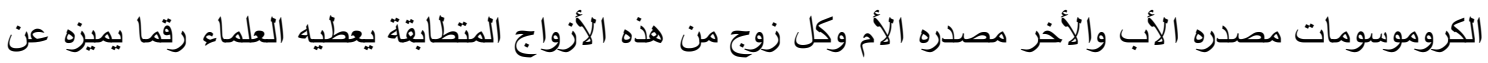
الآخر ابتداءً برقم واحد للزوج الأول إلى الزوج الأخير رقم 23 [9].

DNA 2-2 تتابع نيوكلوتيدات الـ

إن إيجاد طريقة لمعرفة تسلسل تتابعات الحامض النووي DNA أحدث ثورة حقيقية في الوراثة الجزيئية والهندسة الوراثية حيث تزودنا هذه الطريقة بمعلومات مهمة حول تركيب ووظيفة الجين ومن ثم إمكانية تحديد المنتجات التي يشفر لها الجين وتحديد المناطق الحساسة Hot spot لحدوث الطفرات وكذلك تساعد في إيجاد العلاقة التطورية للجينات المتثابهة في الكائن الحي نفسه أو في الكائنات المختلفة والمساعدة في تصنيف الأحياء والفيروسات، وفي عام (1982) نشرت مجلة Nature الخارطة الوراثية لبعض الكائنات وفي عام (2001) نشرت الخارطة الوراثية للانسان [9:[10].

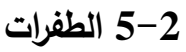

تعرف على إنها التغيرات في النمط الجيني القابلة للتوارث. فلكل كائن حي نمط طبيعي wild type الذي يعد سلالة مرجعية وتتمثل بالإحياء عند عزلها للمرة الأولى، وأي تغيرات تحصل على هذه السلالات تعد طفرات Mutants. والطفرات بدورها تصنف إلى: 1- إضافة insertion أو حذف deletion جزء من المادة النووية وقد تكون منطقة الحذف صغيرة أو كبيرة. 
2- يمكن أن تحصل إضافة أو حذف قاعدة واحدة وهذا ما يطلق عليه الطفرة النقطية. 3- هنالك نمط من الطفرات يدعى الطفرات الصامتة وتحصل عند تغير الثفرة الوراثية أو جزء منها إلى شفرة

$$
\text { وراثية مشفرة للحامض الاميني نفسه [11]. }
$$

الأعمال السابقة

\section{Clelland and et al}

من أولى الطرائق المستخدمة في عملية إخفاء الرسالة السرية باستخدام القواعد النتروجينية[12] إذ أن خوارزميتها تعمل على تصنيع سلسلة DNA بالاعتماد على جدول يتضمن كل الحروف الانكليزية الممثلة بثلاث

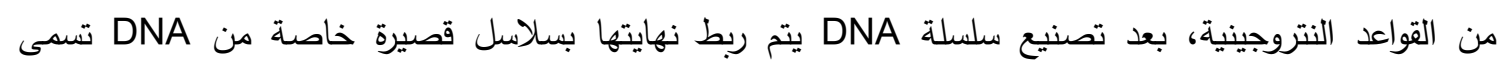

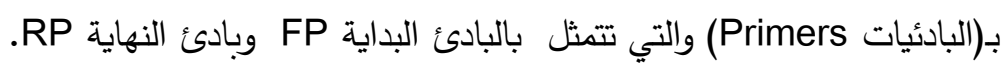

\section{Leier and et al}

نشر Leier وآخرون عام 2000 طريقة جيدة لإخفاء المعلومات [13] وهي طريقة قوية استخدموا فيها بادئات كمفاتيح سرية بين الطرفين، في هذه الطريقة تستخدم سلسلة DNA عامة معروفة لكائن معين وتكون بمثابة مرجع بين الطرفين المرسل والمستلم، إن المستلم بدون البادئات لايمكن أن يسترجع المعلومات ، ولتوضيح الطريقة

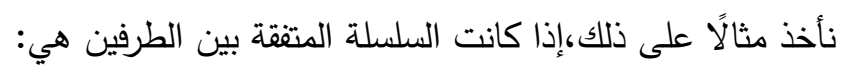

\section{ATGCTTAGTTCCATCGGACTAATGGCCTA}

وإذا كانت البادئات GATTAC ATCAA وكما هو موضح سابقا فان متمم البادئات هو TAGTT

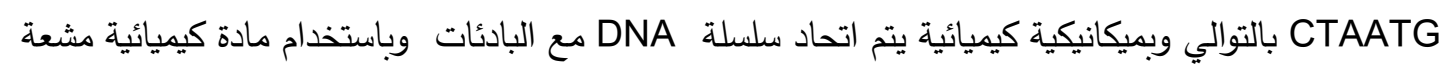

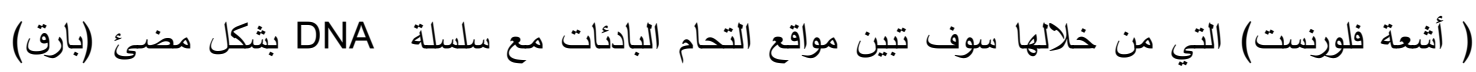
ومواقع غيرمشتركة(غير متحدة) تكون بثكل مظلم، فكان تمثيل مواقع المضئ بتمثيل الثنائي 2(1) ومواقع المظلمة

$$
\begin{aligned}
& \text { بتمثيل الثاني 2(0) فيكون الناتج بشكل الآتي: } \\
& \text { ATGCTTAGTTCCATCGGACTAATGGCCTA }
\end{aligned}
$$$$
\text { ATCAA GATTAC }
$$

$\begin{array}{lllll}0 & 1 & 0 & 1 & 0\end{array}$

فيكون في النهاية سلسلة من الأعداد الثنائية : 01010 والتي تعتبر المعلومة المخفية .

\section{Hung and et al}

إن Hung وآخرون [13] قدموا ثلاث طرائق كلها تستند على وجود سلاسل DNA المعروفة والموجودة في بنوك خاصـة والمعرفة ضمن مواقع الكترونية مثل موقع EMBL إن السلسلة المختارة لجين معين من البنك

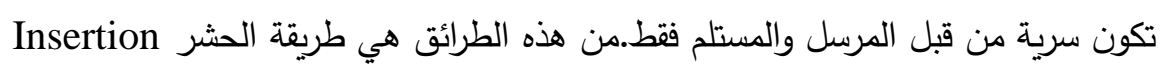

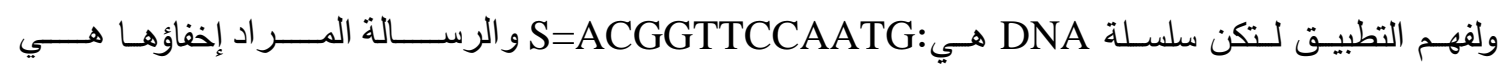
DNA إن طريقة الحشر من الطرائق اليسيرة والسهلة والتي تلخص بمايلي: يتم تحويل سلسلة Mi

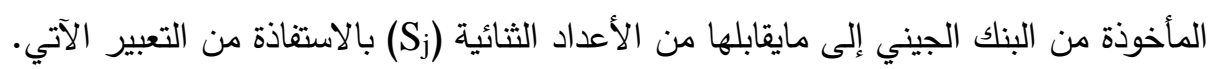
$\mathrm{A} \longleftrightarrow(00)_{2} \mathrm{C} \longleftrightarrow(01)_{2} \quad \mathrm{G} \longleftrightarrow(10)_{2} \quad \mathrm{~T} \longleftrightarrow(11)_{2}$

ثن يتم تقطيع سلسلة الأعداد الثنائية (S $\mathrm{S}_{\mathrm{j}}=00011010111101010000111001$

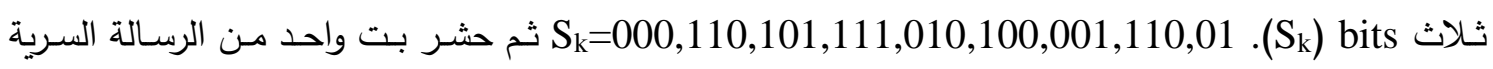

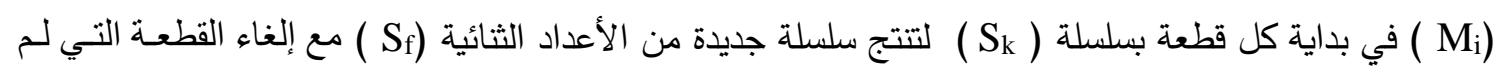
يتم الحشر فيها. 


\section{$\mathrm{S}^{\prime}=$ AATGCCCTGGTAACCG}

تحويل سلسلة الثنائية (Sf) ) إلى سلسلة من القواعد النتروجينية :-

3- خوارزمية الاستبدال في الطفرة الصامتة

تستتد هذه الطريقة إلى فكرة الطفرة الصامتة التي تحدث لسلسلة DNA داخئل دارئل جسم الكائن والتي تتضمن

حدوث طفرة في القاعدة الأخيرة من الكودون لإنتاج نفس الحامض الاميني. والجدول(1) يوضح بان فئن هنالك كودوناً والذي يشفر 20 حامض أميني بمعنى أن هنالك أكثر من كودون ينتج نفس الحامض ألأميني. تم استغلال

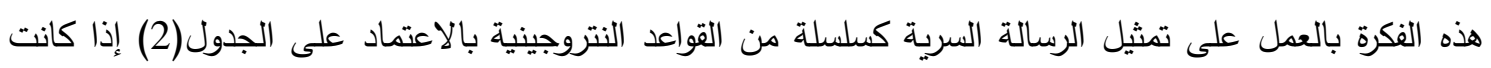
الرسالة نصية، والجدول (3) في حالة الرسالة الصورية، ومن ثم استبدالها في الكودونات القابلة للتغيير والمؤشرة ضمن الجدول(1)(11][11].

جدول (1). الكودونات (المناطق المضللة تمثل الكودونات التي تتتج نفس الحامض الأميني)

\begin{tabular}{|c|c|c|c|c|c|}
\hline \multicolumn{6}{|c|}{ القاعدة الأولى } \\
\hline $\mathrm{G}$ & A & $\mathrm{C}$ & $\mathrm{T}$ & & \multirow{17}{*}{ "E. } \\
\hline TGT Cys[C] & TAT Tyr[Y] & TCT Ser[S1] & TTT Phe[F] & $\mathrm{T}$ & \\
\hline TGC Cys[C] & TAC Tyr[Y] & TCC Ser[S2] & TTC Phe[F] & & \\
\hline TGA Stop[O] & TAA Stop[O] & TCA Ser[S3] & TTA Leu[L4] & & \\
\hline TGG Try[W] & TAG Stop[O] & TCG Ser[S4] & TTG Leu[L5] & & \\
\hline CGT Arg[R1] & CAT His[H] & CCT Pro[P1] & CTT Leu[L1] & $\mathrm{C}$ & \\
\hline CGC Arg[R2] & CAC His[H] & CCC Pro[P2] & CTC Leu[L2] & & \\
\hline CGA Arg[R3] & CAA Gln[Q] & CCA Pro[P3] & CTA Leu[L3] & & \\
\hline CGG Arg[R4] & $\mathrm{CAG} \operatorname{Gln}[\mathrm{Q}]$ & CCG Pro[P4] & CTG Leu[L4] & & \\
\hline AGT Ser[S5] & AAT Asn[N] & ACT Thr[T1] & ATT lle[I] & A & \\
\hline AGC Ser[S6] & $\mathrm{AAC} A \sin [\mathrm{N}]$ & ACC Thr[T2] & ATC lle[I] & & \\
\hline AGA $\operatorname{Arg}[R 5]$ & AAA Lys[K] & AGA Thr[T3] & ATA lle[I] & & \\
\hline AGG Arg[R5] & AAG Lys[K] & ACG $\operatorname{Thr}[\mathrm{T} 4]$ & ATG Met[M] & & \\
\hline GGT Gly[G1] & GAT Asp[D] & GCT Ala[A1] & GTT Val[V1] & G & \\
\hline GGC Gly[G2] & GAC Asp[D] & GCC Ala[A2] & GTC Val[V2] & & \\
\hline GGA Gly[G3] & GAA Glu[E] & GCA Ala[A3] & GTA Val[V3] & & \\
\hline GGG Gly[G4] & GAG Glu[E] & GCG Ala[A4] & GTG Val[V4] & & \\
\hline
\end{tabular}

جدول (2). نموذج يوضح ترميز الرسالة النصية وفق طريقة الاستبدال في الطفرة الصامتة

\begin{tabular}{|c|c|c|c|c|c|c|c|}
\hline Symbol & Codon & Symbol & Codon & Symbol & Codon & Symbol & Codon \\
\hline A & AAA & Q & CAA & 6 & GAA & - & TAA \\
\hline B & AAC & R & CAC & 7 & GAC & $/$ & TAC \\
\hline C & AAG & S & CAG & 8 & GAG & $@$ & TAG \\
\hline D & AAT & T & CAT & 9 & GAT & $!$ & TAT \\
\hline E & ACA & U & CCA & $*$ & GCA & $\#$ & TCA \\
\hline F & ACC & V & CCC & $\&$ & GCC & $\wedge$ & TCC \\
\hline G & ACG & W & CCG & + & GCG &, & TCG \\
\hline H & ACT & X & CCT & Space & GCT & $;$ & TCT \\
\hline I & AGA & Y & CGA & $>=$ & GGA & “ & TGA \\
\hline J & AGC & Z & CGC & $<=$ & GGC & $:$ & TGC \\
\hline K & AGG & 0 & CGG & $=$ & GGG & $\vdots$ & TGG \\
\hline L & AGT & 1 & CGT & $\cdot$ & GGT & $\sim$ & TGT \\
\hline M & ATA & 2 & CTA & $\#$ & GTA & ] & TTA \\
\hline N & ATC & 3 & CTC & $\%$ & GTC & {[} & TTC \\
\hline O & ATG & 4 & CTG & ( & GTG & $\bullet$ & TTG \\
\hline P & ATT & 5 & CTT & ) & GTT & $\sim$ & TTT \\
\hline
\end{tabular}


جدول (3). نموذج يوضح ترميز الرسالة الصورية وفق طريقة الاستبدال في الطفرة الصامتة

\begin{tabular}{|c|c|c|c|c|c|c|c|c|c|}
\hline $\begin{array}{l}\text { Pixel } \\
\text { value }\end{array}$ & Sequence & $\begin{array}{l}\text { Pixel } \\
\text { value }\end{array}$ & Sequence & $\begin{array}{l}\text { Pixel } \\
\text { value }\end{array}$ & Sequence & $\begin{array}{l}\text { Pixel } \\
\text { value }\end{array}$ & Sequence & $\begin{array}{l}\text { Pixel } \\
\text { value }\end{array}$ & Sequence \\
\hline 0 & AAAA & 51 & ATAT & 102 & CGCG & 153 & GCGC & 204 & TATA \\
\hline 1 & AAAC & 52 & ATCA & 103 & CGCT & 154 & GCGG & 205 & TATC \\
\hline 2 & AAAG & 53 & ATCC & 104 & CGGA & 155 & GCGT & 206 & TATG \\
\hline 3 & AAAT & 54 & ATCG & 105 & CGGC & 156 & GCTA & 207 & TATT \\
\hline 4 & AACA & 55 & ATCT & 106 & CGGG & 157 & GCTC & 208 & TCAA \\
\hline 5 & AACC & 56 & ATGA & 107 & $\begin{array}{l}\text { CGGT } \\
\end{array}$ & 158 & GCTG & 209 & TCAC \\
\hline 6 & AACG & 57 & ATGC & 108 & CGTA & 159 & GCTT & 210 & TCAG \\
\hline 7 & AACT & 58 & ATGG & 109 & CGTC & 160 & GGAA & 211 & TCAT \\
\hline 8 & AAGA & 59 & ATGT & 110 & CGTG & 161 & GGAC & 212 & TCCA \\
\hline 9 & AAGC & 60 & ATTA & 111 & CGTT & 162 & GGAG & 213 & TCCC \\
\hline 10 & AAGG & 61 & ATTC & 112 & CTAA & 163 & GGAT & 214 & TCCG \\
\hline 11 & AAGT & 62 & ATTG & 113 & CTAC & 164 & GGCA & 215 & TCCT \\
\hline 12 & AATA & 63 & ATTT & 114 & CTAG & 165 & GGCC & 216 & TCGA \\
\hline 13 & AATC & 64 & CAAA & 115 & CTAT & 166 & GGCG & 217 & TCGC \\
\hline 14 & AATG & 65 & CAAC & 116 & CTCA & 167 & GGCT & 218 & TCGG \\
\hline 15 & AATT & 66 & CAAG & 117 & CTCC & 168 & GGGA & 219 & TCGT \\
\hline 16 & ACAA & 67 & CAAT & 118 & CTCG & 169 & GGGC & 220 & TCTA \\
\hline 17 & ACAC & 68 & CACA & 119 & CTCT & 170 & GGGG & 221 & TCTC \\
\hline 18 & ACAG & 69 & CACC & 120 & CTGA & 171 & GGGT & 222 & TCTG \\
\hline 19 & ACAT & 70 & CACG & 121 & CTGC & 172 & GGTA & 223 & TCTT \\
\hline 20 & ACCA & 71 & CACT & 122 & CTGG & 173 & GGTC & 224 & TCAA \\
\hline 21 & $\mathrm{ACCC}$ & 72 & CAGA & 123 & CTGT & 174 & GGTG & 225 & TGAC \\
\hline 22 & ACCG & 73 & CAGC & 124 & CTTA & 175 & GGTT & 226 & TGAG \\
\hline 23 & ACCT & 74 & CAGG & 125 & CTTC & 176 & GTAA & 227 & TGAT \\
\hline 24 & ACGA & 75 & CAGT & 126 & CTTG & 177 & GTAC & 228 & TGCA \\
\hline 25 & ACGC & 76 & CATA & 127 & CTTT & 178 & GTAG & 229 & TGCC \\
\hline 26 & ACGG & 77 & CATC & 128 & GAAA & 179 & GTAT & 230 & TGCG \\
\hline 27 & ACGT & 78 & CATG & 129 & GAAC & 180 & GTCA & 231 & TGCT \\
\hline 28 & ACTA & 79 & CATT & 130 & GAAG & 181 & GTCC & 232 & TGGA \\
\hline 29 & ACTC & 80 & CCAA & 131 & GAAT & 182 & GTCG & 233 & TGGC \\
\hline 30 & ACTG & 81 & CCAC & 132 & GACA & 183 & GTCT & 234 & TGGG \\
\hline 31 & ACTT & 82 & CCAG & 133 & GACC & 184 & GTGA & 235 & TGGT \\
\hline 32 & ACAA & 83 & CCAT & 134 & GACG & 185 & GTGC & 236 & TGTA \\
\hline 33 & AGAC & 84 & CAAA & 135 & GACT & 186 & GTGG & 237 & TGTC \\
\hline 34 & AGAG & 85 & CCCA & 136 & GAGA & 187 & GTGT & 238 & TGTG \\
\hline 35 & AGAT & 86 & $\mathrm{CCCC}$ & 137 & GAGC & 188 & GTTA & 239 & TGTT \\
\hline 36 & AGCA & 87 & $\mathrm{CCCG}$ & 138 & GAGG & 189 & GTTC & 240 & TTAA \\
\hline 37 & AGCC & 88 & CCCT & 139 & GAGT & 190 & GTTG & 241 & TTAC \\
\hline 38 & AGCG & 89 & CCGA & 140 & GATA & 191 & GTTT & 242 & TTAG \\
\hline 39 & AGCT & 90 & CCGC & 141 & GATC & 192 & TAAA & 243 & TTAT \\
\hline 40 & AGGA & 91 & CCGG & 142 & GATG & 193 & TAAC & 244 & TTCA \\
\hline 41 & AGGC & 92 & CCGT & 143 & GATT & 194 & TAAG & 245 & TTCC \\
\hline 42 & AGGG & 93 & CCTA & 144 & GCAA & 195 & TAAT & 246 & TTCG \\
\hline 43 & AGGT & 94 & CCTC & 145 & GCAC & 196 & TACA & 247 & TTCT \\
\hline 44 & AGTA & 95 & CCTT & 146 & GCAG & 197 & TACC & 248 & TTGA \\
\hline 45 & AGTC & 96 & CGAA & 147 & GCAT & 198 & TACG & 249 & TTGC \\
\hline 46 & AGTG & 97 & CGAC & 148 & GCCA & 199 & TACT & 250 & TTGG \\
\hline 47 & AGTT & 98 & CGAG & 149 & GCCC & 200 & TAGA & 251 & TTGT \\
\hline 48 & ATAA & 99 & CGAT & 150 & GCCG & 201 & TAGC & 252 & TTTA \\
\hline 49 & ATAC & 100 & CGCA & 151 & GCCT & 202 & TAGG & 253 & TTTC \\
\hline 50 & ATAG & 101 & CGCC & 152 & GCGA & 203 & TAGT & 254 & TTTG \\
\hline 255 & TTTT & & & & & & & & \\
\hline
\end{tabular}


DNA 1-3 عملية الإخفاء ضمن سلسلة

تتكون خوارزمية الإخفاء من أربع مراحل كما في الثكل (2).

المرحلة الأولى: اختيار وتهيئة سلسلة DNA

Si DNA المدخلات: سلسلة

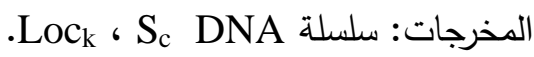

الخطوات : كما ذكرنا سابقا إن الكائنات الحية تتقسم على قسمين وهما بدائية النواة وحقيقة النواة، وأن سلسلة DNA في حقيقة النواة تكون موجودة ضمن النواة وعلى شكل كروموسومات وبأعداد مختلفة

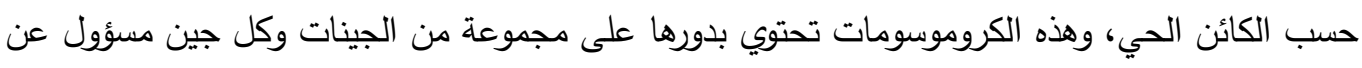

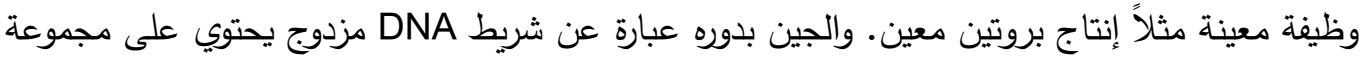

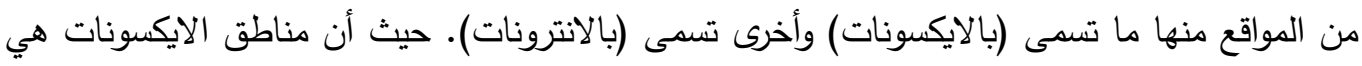

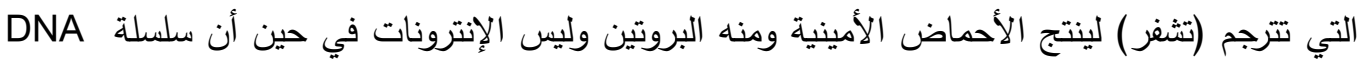

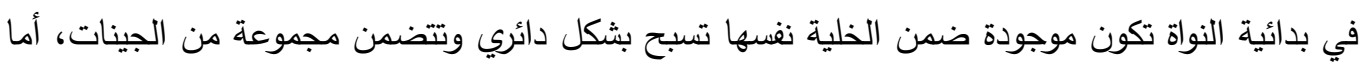
الفرق عن حقيقة النواة أنها لا تحتوي على انترونات بل مناطق الايكسونات فقط التي تشفر مباشرة إلى لى

أحماض أمينية.

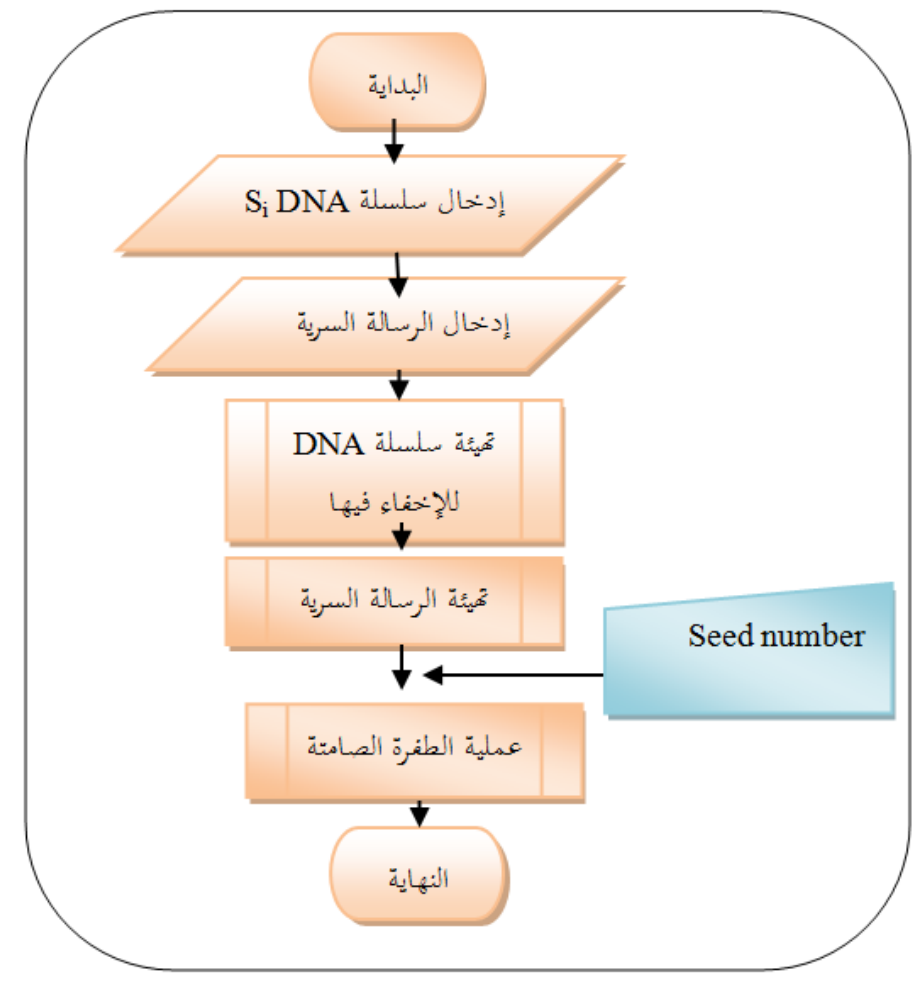

الثكل (2). الدخطط العام لإخفاء الرسالة ضمن سلسلة DNA (طريقة استبدال الطفرة الصامتة)

إذا كان الاختيار لسلسلة DNA من حقيقة النواة فيتم اختيار رقم الكروموسوم ومنه الذراع ومنه رقم الجين ومنه

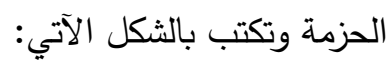



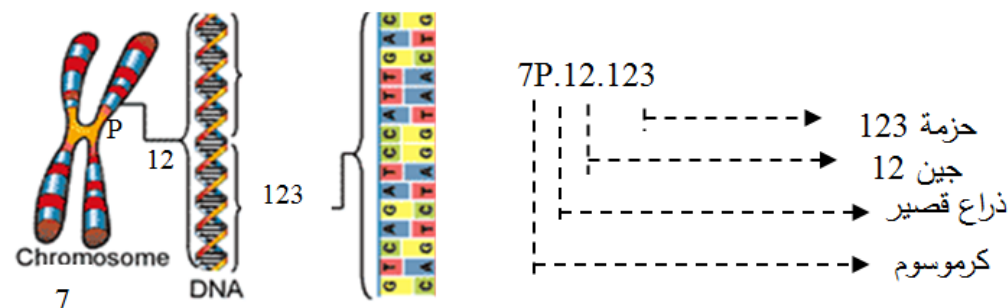

يمكن الاستفادة من بعض المواقع التي تتشر معلومات عن تسلسلات DNA للبروتينات والإنزيمات ومنها موقع (10] (EBI)

في حالة حقيقية النواة فيتم اختيار جين مسؤول عن إنتاج بروتين معين ونجري عليه ما يجري عليه داخل

$$
\text { الكائن الحي وهي: }
$$

1- عملية الاستساخ: إن سلسلة DNA المأخوذة في الموقع EBI هي عبارة عن سلسلة أحادية على العيل

اعتبار أن السلسلة الأخرى متممة لهذه السلسلة.

2- عملية العزل أو الفصل: يتم فصل أو قطع مناطق الإنترونات من السلسلة وتبقى فقط مناطق

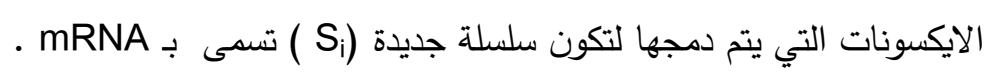

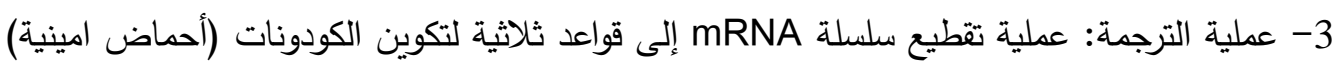

$$
\text { لتكون لنا سلسلة جديدة من الكودونات (Sc) والتي تستخدم لإخفاء الرسالة السرية . }
$$

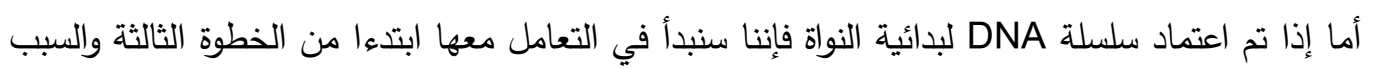

يعود على إنها تحتوي على مناطق الايكسونات فقط. والثكل (3) يمثل المخطط الانسيابي لعملية تهيئة

$$
\text { السلسلة. }
$$

بالإمكان البحث في سلسلة Sc مواقع الكودونات القابلة لإنتاج نفس الحامض الاميني والاحتفاظ بهذا الموقع في مصفوفة خاصة (LOCk) لغرض الاستفادة منه لاحقا في الإخفاء ضمن الصورة.

المرحلة الثانية: تكوين الجدول وتهيئة الرسالة السرية (مرحلة الترميز)

المدخلات: سلسلة Si DNA ، الرسالة السرية.

المخرجات: سلسلة MN" DNA (التي تمثل الرسالة السرية).

الخطوات: خلال هذه المرحلة يتم تكوين الجدول لترميز الرسالة السرية إلى ما يقابلها من سلسلة قصير لرساله

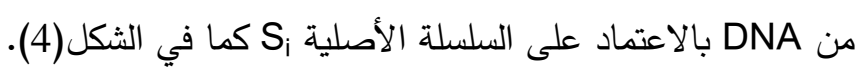

فإذا كانت الرسالة نصية فيتم تقطيع السلسلة إلى قواعد ثلاثية وحسب مالئ ما يقابلها من الأحرف

الأبجدية بالإضافة إلى الرموز والأرقام وكما في الجدول (2). أما إذا كانت الرسالة صورية فيتم ترميزها

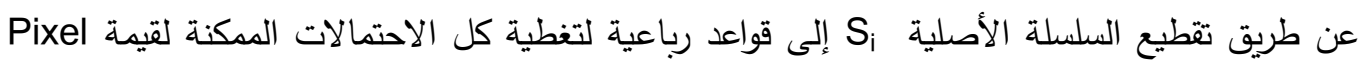
التي تمثل عنصر الصورة وهكذا بالتتابع وكما في الجدول (3). في كلا الحالتين ( إذا كانت الرسالة

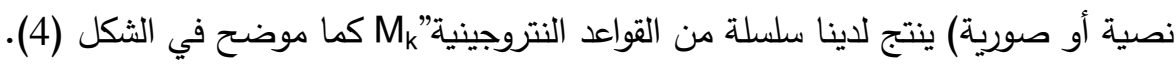




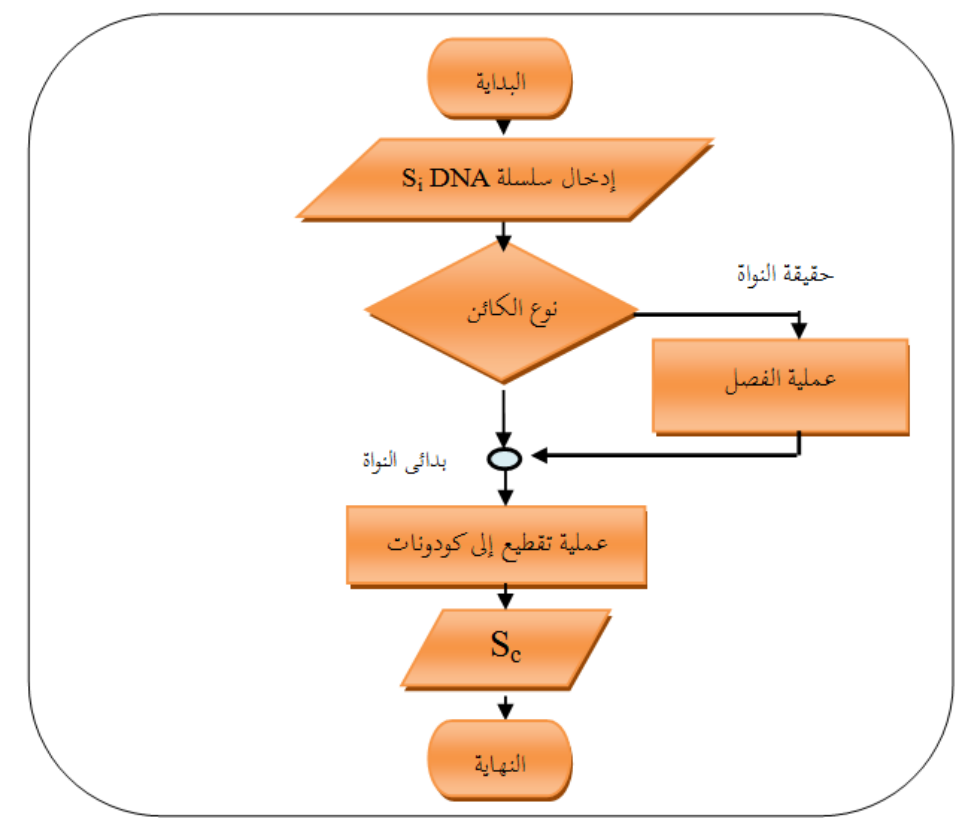

الثكل(3). يمثل المخطط الانسيابي لعملية تهيئة سلسلةDNA

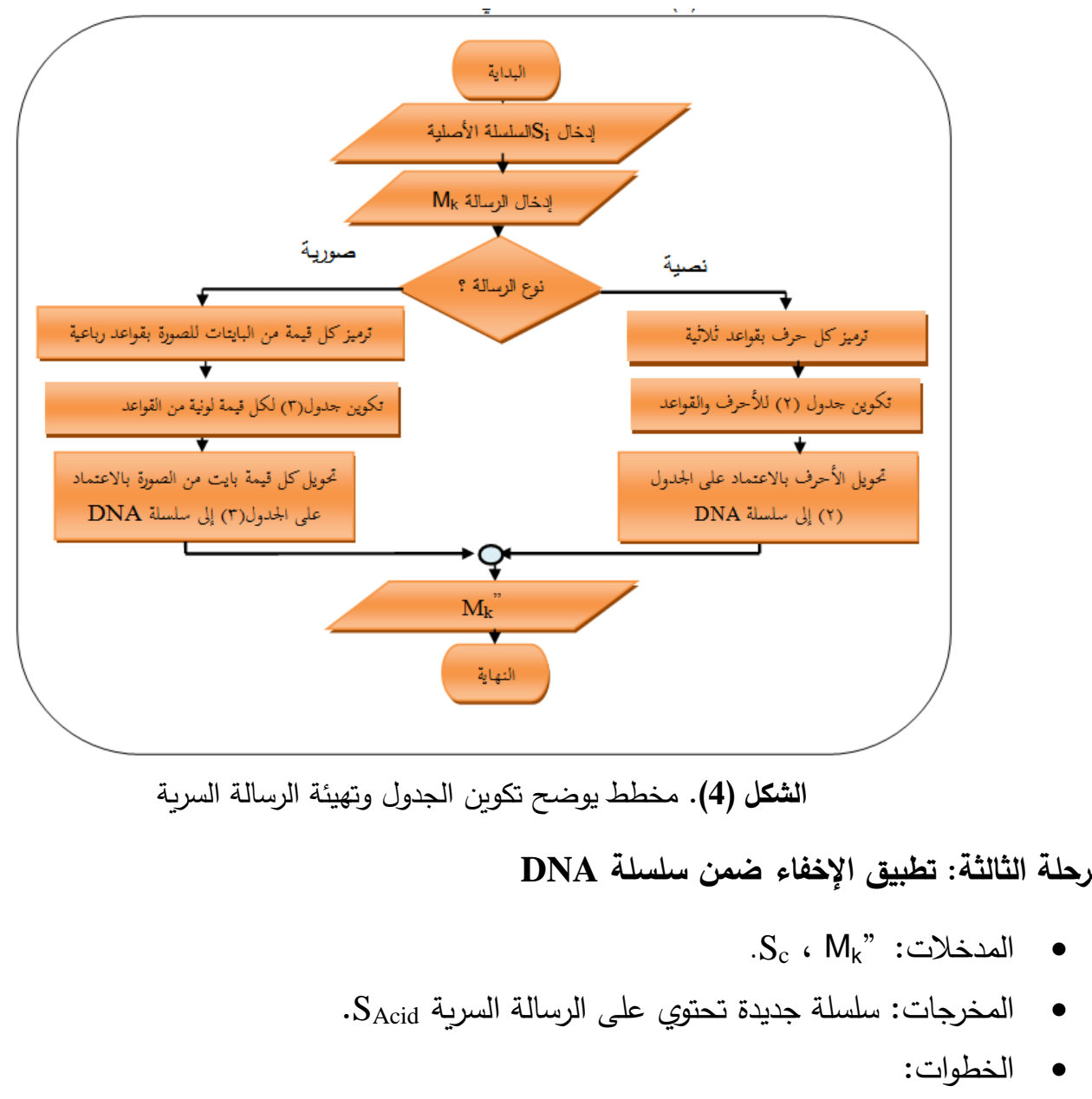

1- خطوة اختيارية لزيادة سرية الإخفاء وهو اختيار البذرة Seed number لتحديد الموقع الذي بدأ منه

عملية إخفاء الرسالة السرية. 
2- البحث في سلسلة Sc Sن الكودونات القابلة لإنتاج نفس الحامض الاميني حسب الجدول(1)

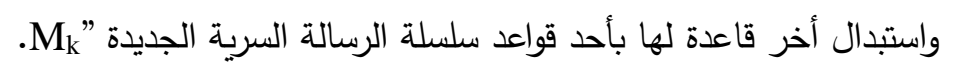

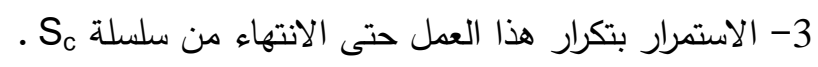

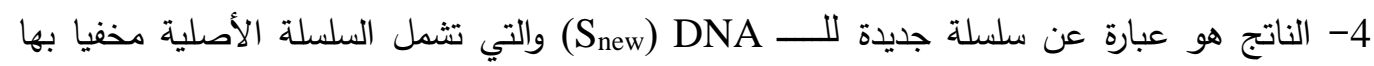
الرسالة السرية. والثكل(5) يبين الخطوات للمرحلة الثالثة.

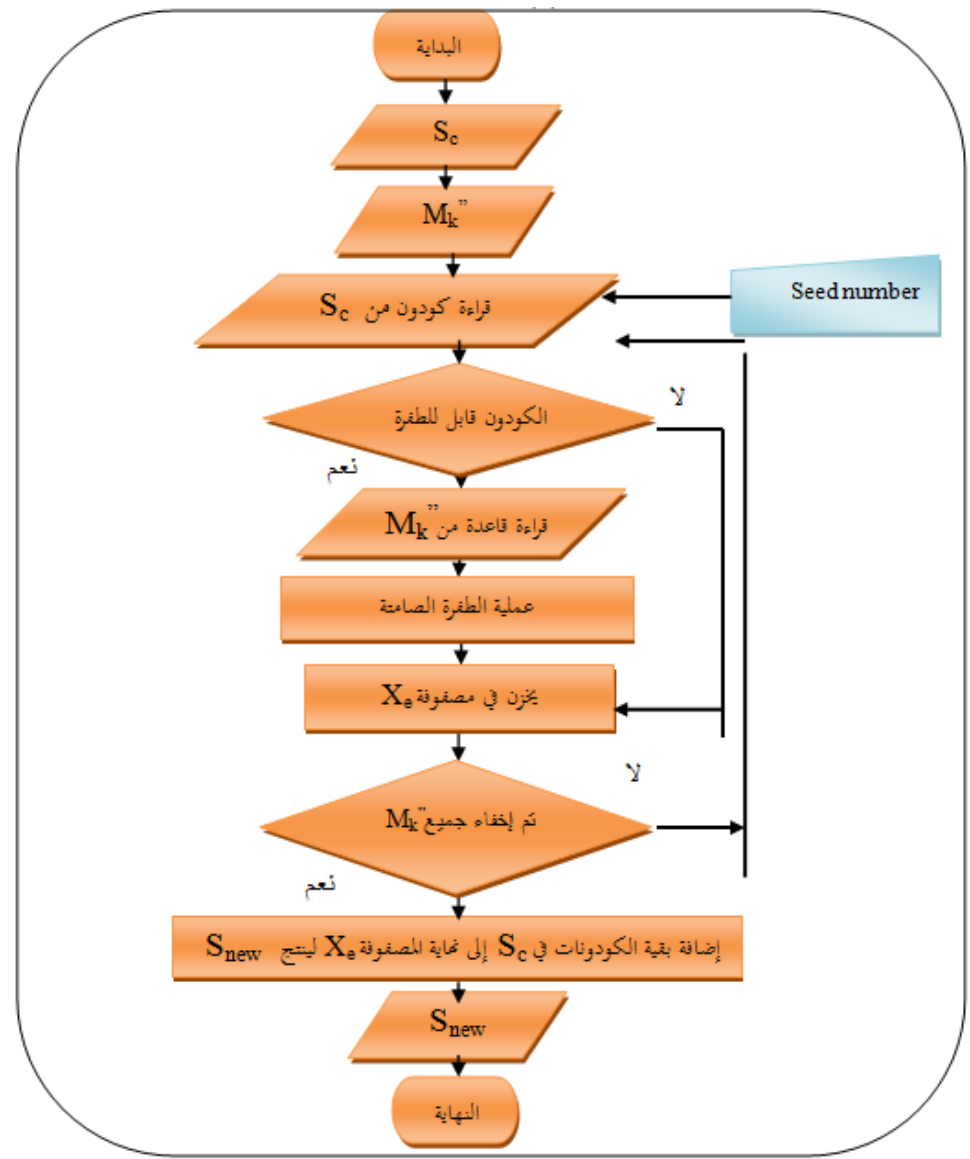

الثكل (5). مخطط يوضح عملية الإخفاء ضمن سلسلة DNA

المرحلة الرابعة: طرائق الإرسال

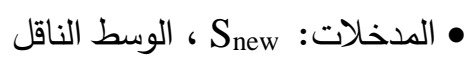

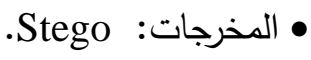

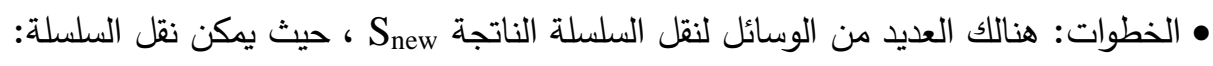

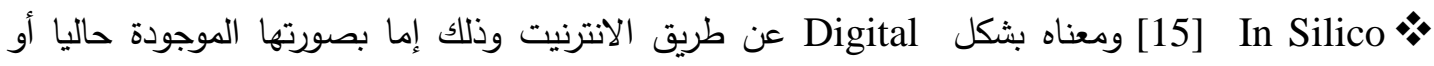
إخفائها في أحدى ملفات الوسائط المتعددة (Multimedia) لزيادة قوة الإخفاء.

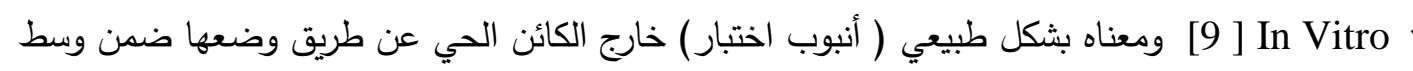
خاص وهذا يتطلب وجود فريق مختص من كلا الفريقين (علوم الحاسوب وعلوم الحياة).

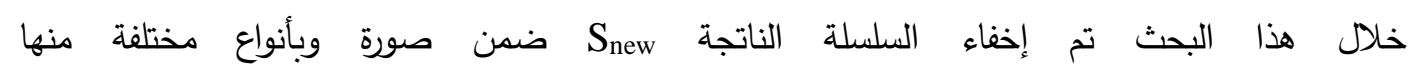
باستغلال تقنية البت الأقل أهمية (PNG , BMP) 
3-3 مثال توضيحي لطريقة الاستبدال في الطفرة الصامتة (عملية الإخفاء)

للتوضيح يمكن اختيار سلسلةDNA بدائية النواة لبكتيريا( إيكولاي EBColi ) معروفة التسلسل من الموقع EBI على إن يتم الاتفاق عليها بين الطرفين. $\mathrm{S}_{\mathrm{i}}=$ ATGAACGGCTCGCCCGGTCTGGTCTACATGGAGTCGGTGGCC...

بعد تقطيع سلسلة SAG إلى كودونات تتتج سلسلة جديدة SACG $\mathrm{S}_{\mathrm{c}}=\mathrm{ATG}$ AAC GGC TCG CCC GGT CTG GTC TAC ATG GAG TCG GTG GCC

لغرض تحديد طول الرسالة السرية(النصية) (Mk) تم إضافة ! إلى نهاية الرسالة. $M_{k}=$ Silent Mutation Method!

$\mathrm{M}_{\mathrm{k}}=$ CAG AGA AGT ACA ATC CAT

بعد ترميز كل حرف وبما يقابلها من الكودون حب الجدول(2) TAT.

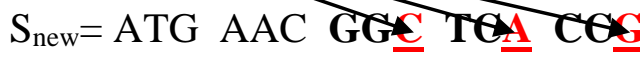

عملية إخفاء M

بالإمكان استخدام جدول(1) لتحويل سلسلة Snew

$\mathrm{S}_{\text {Acid }}=\mathrm{MNG} 2 \mathrm{~S} 3 \mathrm{P} 4$.

3-3 الإخفاء في الصور الملونة

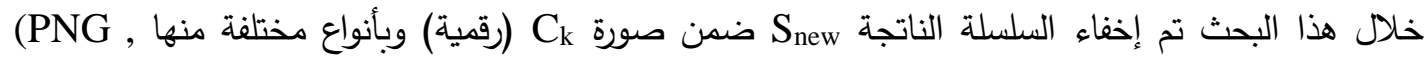
باستغلال تقنية البت الأقل أهمية (LSB) وبتقنية عشوائية والثكل (6) يوضح المخطط العام لعملية

الإخفاء والتي تمر بثلاث مراحل.

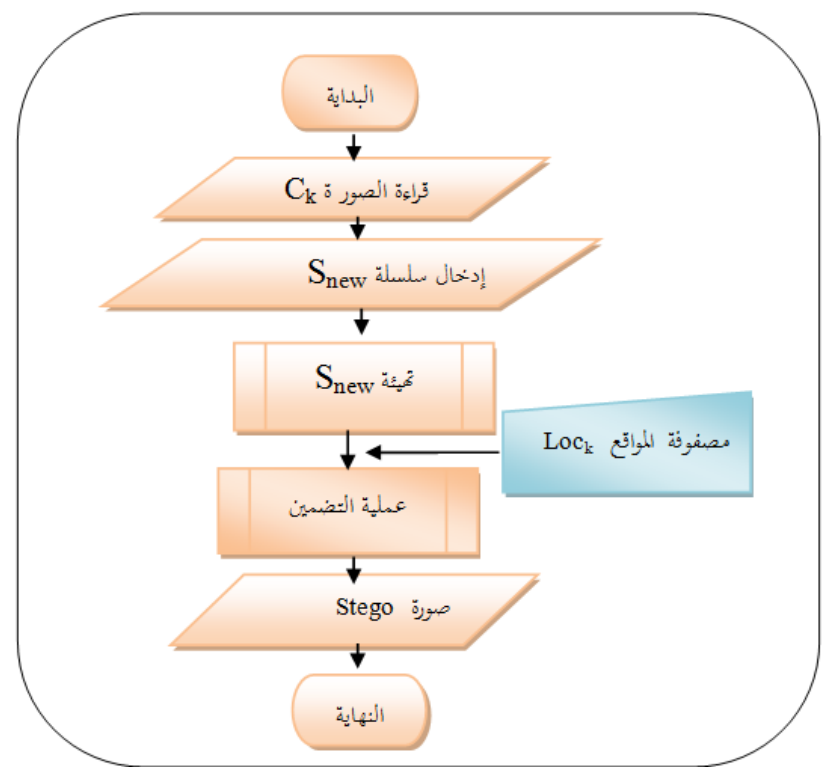

الثكل(6). مخطط العام لعملية الإخفاء ضمن الصورة ملونة

المرحلة الأولى: تهيئة سلسلة Snew.

• المدخلات:سلسلة Snew.

• المخرجات: سلسلة ثنائية S. 


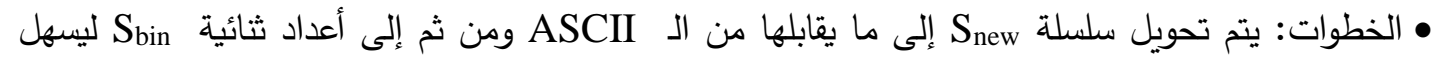

إخفائها ضمن الغطاء كما في الثكل (7).

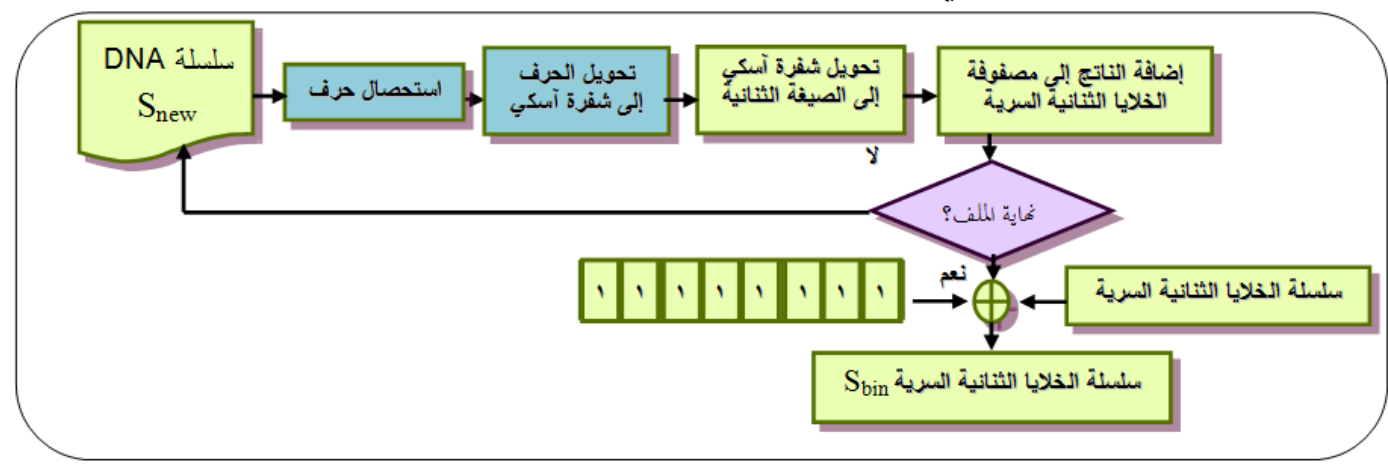

S الثكل (7). عملية نهيئة السلسلة

المرحلة الثانية: اختيار الغطاء Cn

يتم اختيار صورة غطاء C C C مناسب بحجم الرسالة المرسلة.

المرحلة الثالثة: عملية الإخفاء

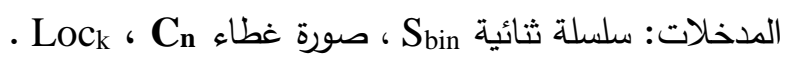

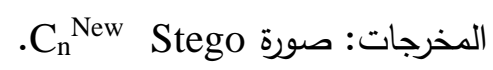

الخطوات: اختيار المواقع ضمن الصورة للإخفاء حسب قيم مصفوفة المواقع Lock.

إذا كان عدد مواقع المصفوفة LoC غير كاف لإتمام العملية يصار إلى إضافة قيم LoC الأولية إلى قيم الأخيرة بحيث تتتج قيم جديدة للا Lock

$$
\text { Lock }=[2,5,7,8,12 \ldots \ldots . \ldots 350][352,355,357,358,362 .
$$

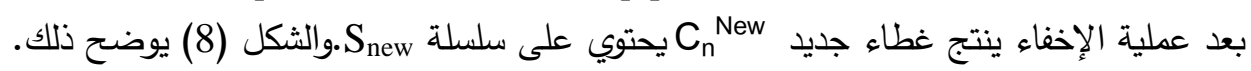

$$
\text { 4-3 استرجاع سلسلة DNA من الصور الملونة }
$$

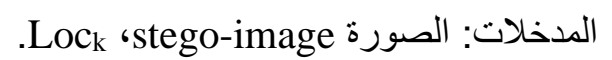

المخرجات: سلسلة المخلة:

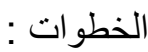

1- معرفة المواقع العشوائية المتفق عليها بين الطرفين Lock.

2- من خلال أول 16 بت والمتضمنة طول الرسالة الثنائية X، بالاعتماد عليها وعلى Lock تنتج مصفوفة

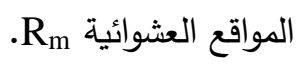

3- قراءة بايت من الصورة ومقارنتها مع مواقع Rm فإذا كانت مطابقة يتم استحصال البت الأول (LSB)

$$
\text { من البايت ووضعها ضمن المصفوفة جديدة. }
$$

4- نستمر بالعملية السابقة ولحين الوصول إلى (البايت=255) والتي تدل على على نهاية الرسالة ضمن الصورة عندها تتم عملية خزن السلسلة الثنائية ضمن المصفوفة Bin والثكل (9) يوضح لكئ لك. 
5- تحويل المصفوفة الثنائية Bin إلى character's (أحرف) وخزن النتيجة النهائية ضمن ملف نصي S والثكل (10) يوضح عملية تحويل السلسلة الثنائية إلى أحرف

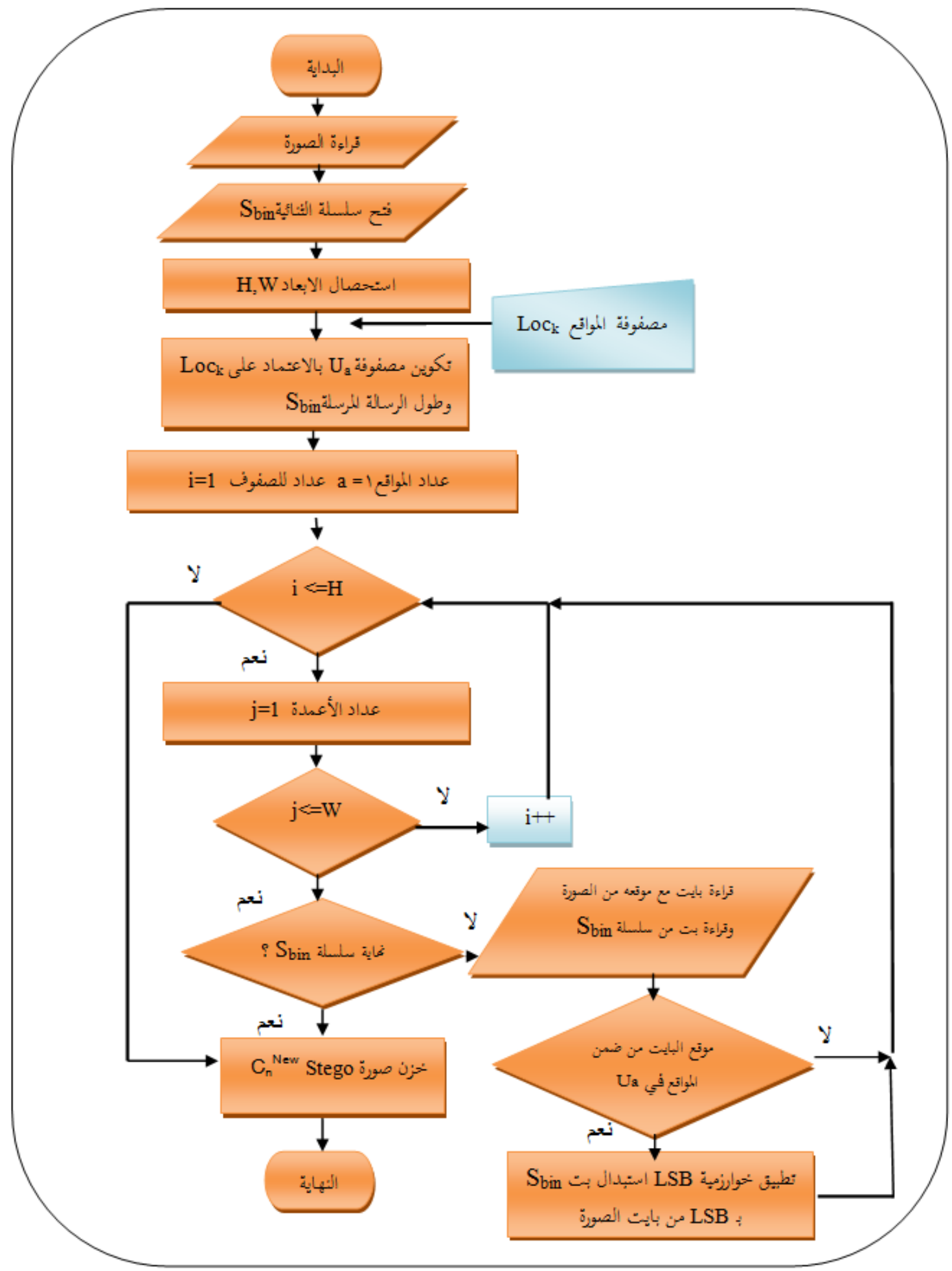

BMP،PNG الثكل (8). عملية الإخفاء ضمن الصورة بنوعيها 


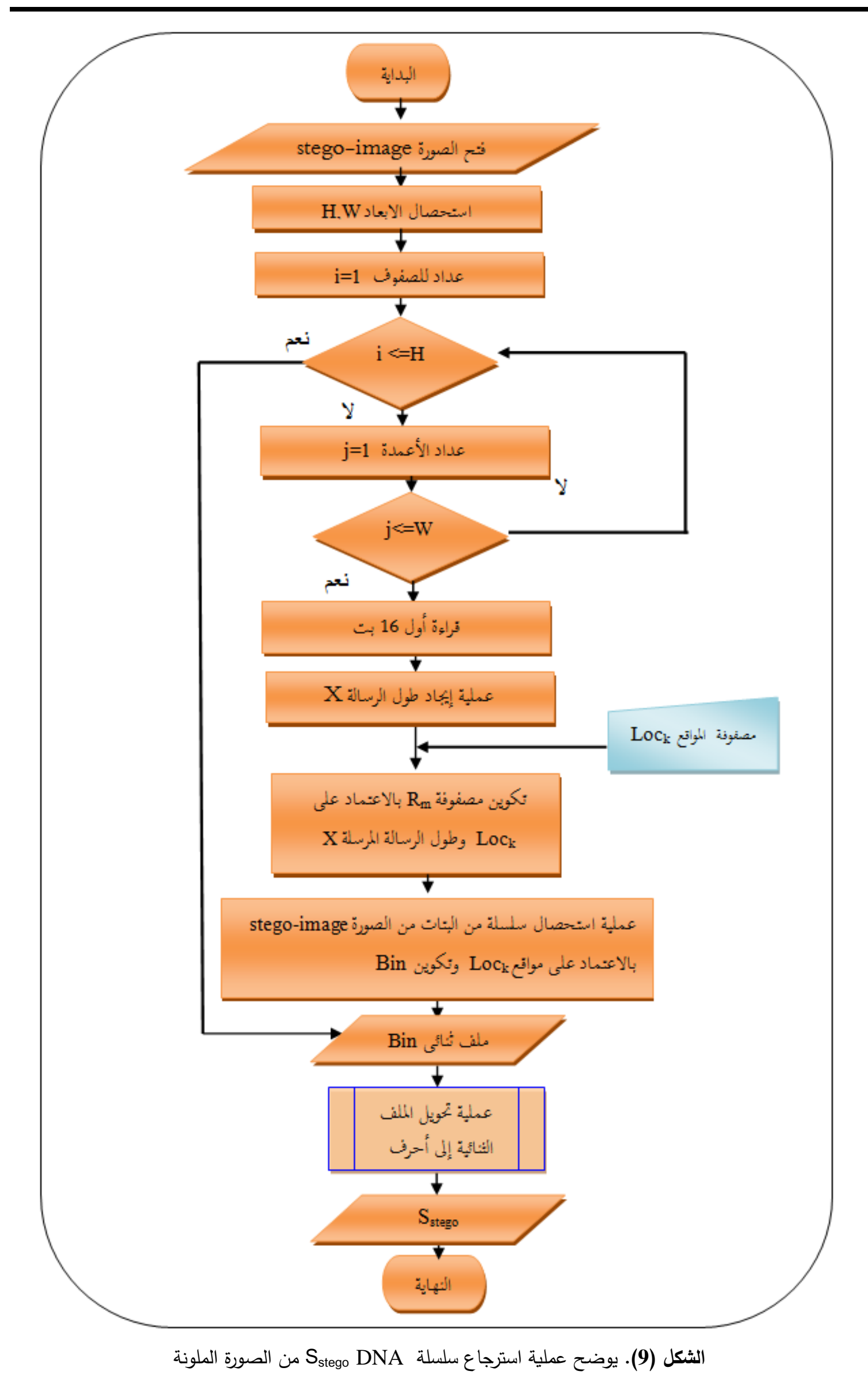




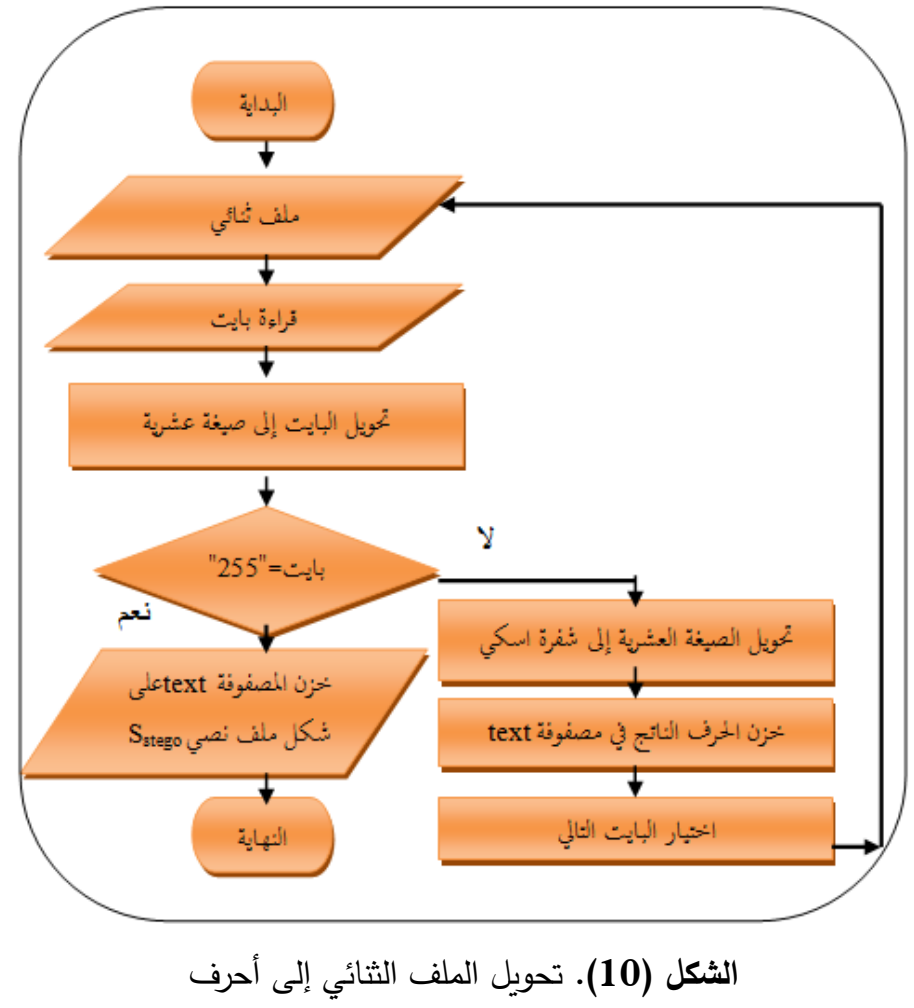

S S-3-3 DNA استرجاع الرسالة السرية من سلسلة

$$
\begin{aligned}
& \text { • المدخلات: ملف نصي (سلسلة S }
\end{aligned}
$$

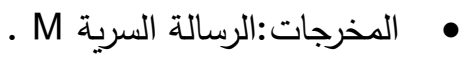

$$
\begin{aligned}
& \text { • الخطوات : }
\end{aligned}
$$

إذا كان الإرسال عبارة عن سلسلة من الأحماض الامينية في البداية يجب تحويل سلسلة Stego

$$
\text { 1- سلسلة DNA بالاعتماد على الجدول (1). }
$$

2- يتم البحث في السلسلة عن الكودونات القابلة لإنتاج نفس الحامض الاميني واستحصال أخر قاعدة

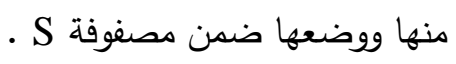

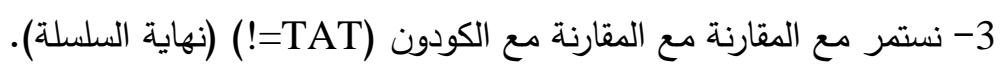

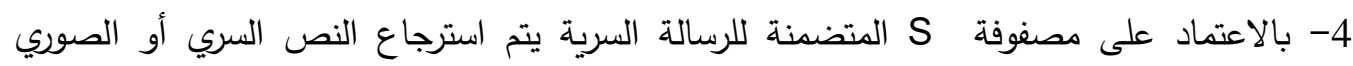
بالاعتماد على الجدولين ((2) و (3)). والثكل(11) يوضح عملية استرجاع الرسالة السرية.

3-6 مثال توضيحي لاسترجاع الرساية السرية لطريقة استبدال الطفرة الصامتة لاسترجاع الرسالة السرية من سلسلة SNA

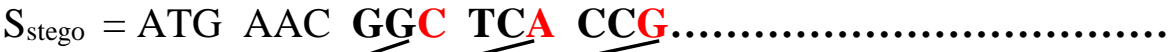

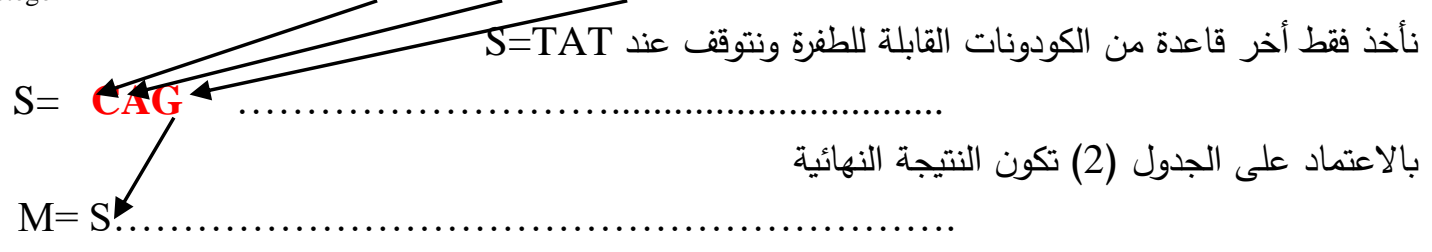




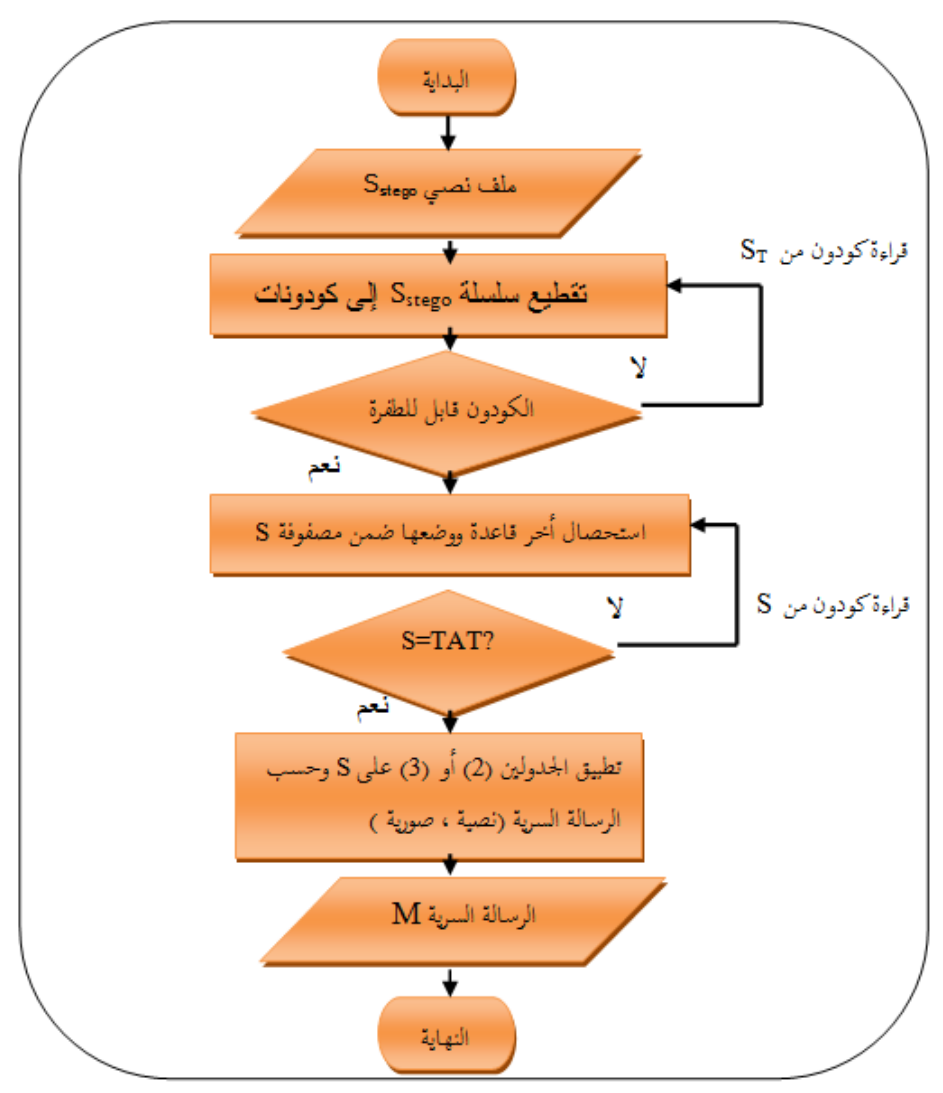

S الثكل (11). استرجاع الرسالة السرية من سلسلة

- 4

هنالك العديد من الاختبارات والمقاييس لإخفاء الرسالة السرية ( نصية وصورية) بأحجام وبأطوال مختلفة ضمن

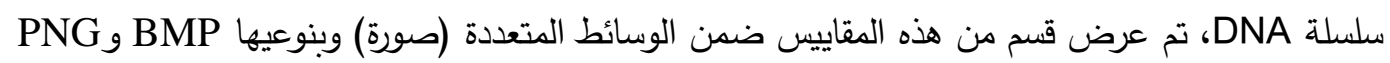

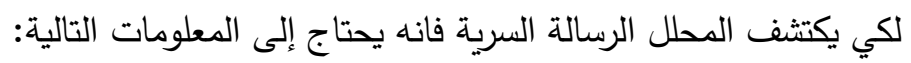

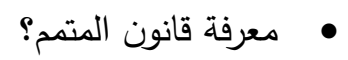

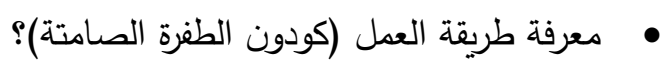

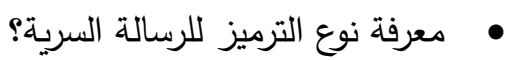

DNA 1-4 مقاييس تتعلق بسلسلة 1- تحليل القوة: وتعني احتمالية Cracking) تخمين المتطفل للوصول إلى الرسالة السرية الموجودة [13].DNA ضمن سلسلة

فإذا كانت الرسالة المرسلة نصاً تكون الاحتمالية بمعادلة الآتية:

Crack probability $=1 / \mathrm{L} * 1 / \mathrm{P} * 1 / \mathrm{C}$

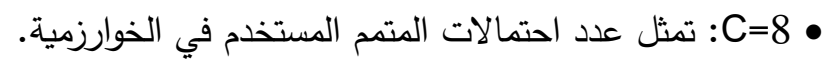
• • P=64: تمثل احتمالية ترميز الأحرف كما في الجدول (4-2) •

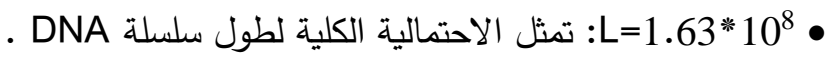
إضافة إلى وجود بعض المفاتيح في حالة استخدام سلسلة DNA لكائن بدائي النواة أو حقيقي النواة 


\begin{tabular}{|c|c|}
\hline مفاتيح بدائي النواة & مفاتيح حقيقي النواة \\
\hline 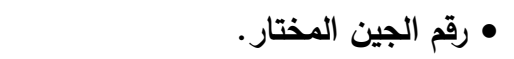 & 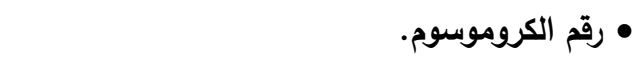 \\
\hline • اختيار رقم البدرة (Seed number) . & 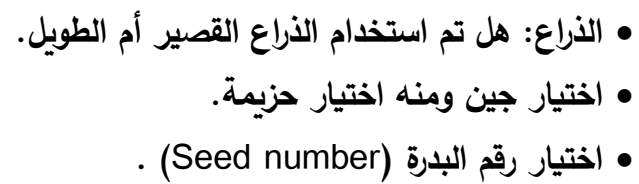 \\
\hline
\end{tabular}

أما اذا الرسالة المرسلة عبارة عن صورة فتكون المعادلة :

Crack probability $=1 / \mathrm{L} * 1 / \mathrm{P} * 1 / \mathrm{C}$

في هذه الحالة تكون الاحتمالية كما سبق في حالة الرسالة النصية ماعدا:

! P=256! : تمثل احتمالية ترميز قيم البكسلات كما في الجدول (3). مع بقاء وجود المفاتيح السابقة.

2- تحليل السعة: وتثمل عدة مقاييس:

• السعة Capacity: ويقصد بها طول سلسلة DNA بعد إضافة الرسالة السرية

السعة = طول سلسلة DNA للجين

• الحمل Upload : ويقصد به مقدار الكمية المضافة إلى السلسلة الأصلية.

0 = | (الحمل

المعدل Average : ويقصد به معدل إدخال الرسالة السرية بالنسبة إلى سلسلة DNA الأصلية . (NPC) $M_{i}^{*} \times 2 / S_{i}^{*}=$

$$
\begin{aligned}
& \text { الوحدة التي تقاس بها هي (NPC): قاعدة) (N) لكل كودون (C). }
\end{aligned}
$$

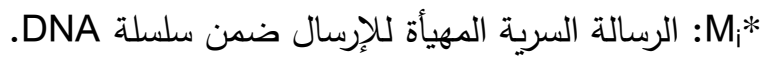

المأس

الجدول(4) يبين بعض الأمثلة التوضيحية لهذه المقاييس لجينات كائنات بدائية النواة معروفة السلسلة ضمن موقع العادين

.EBI

الجدول(4) يبين بعض الأمثلة التطبيقية للمقاييس السابقة لرسالة نصية حجمها KB20

\begin{tabular}{|c|c|c|c|c|}
\hline NPC المعدل NPC & الحمل & السعة & طول السلسلة & الجين \\
\hline 1.22 & 0 & 200117 & 200117 & AC153 \\
\hline 2.46 & 0 & 149884 & 149884 & AC166 \\
\hline 1.19 & 0 & 204841 & 204841 & AC167 \\
\hline 1.28 & 0 & 191456 & 191456 & AC189 \\
\hline
\end{tabular}

في هذه الدراسة تم إضافة مقاييس أخرى هي:

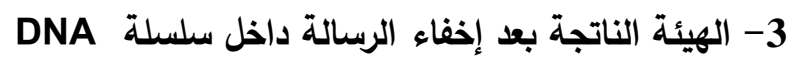
إن الهيئة الناتجة بعد إخفاء الرسالة في سلسلة DNA يتم أرسلها كآلاتي:

$$
\text { بصيغة سلسلة DNA. }
$$

بصيغة سلسلة من الأحماض الأمينية.

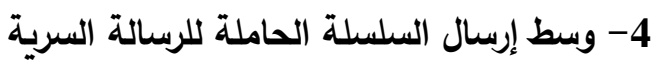

.In Silico • 
. In Vitro •

الجدول(5) يوضح نتائج مقارنة عملنا الحالي مع طرائق أخرى.

الجدول(5) مقارنة بين الطرائق

\begin{tabular}{|c|c|c|c|c|}
\hline هيئة الإرسال & 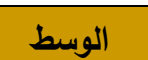 & تعليل السعة & تحليل & الطرائق \\
\hline DNA Dلسلة & غير متوفر & غير منوفر & متوفر & Leier[16,12 ] \\
\hline أرقام حقيقة & غير متوفر & غير متوفر & غير منوفر & Shimanaisky[4] \\
\hline سلسلة مكبوسة DNA & غير متوفر & متوفر & غير متوفر & Chang[13 ] \\
\hline DNA سلسلة & غير متوفر & 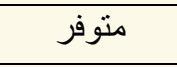 & منوفر & Hung[ 13 ] \\
\hline إما سلسلة DNA أو سلسلة من الأحماض & متوفر & متوفر & متوفر & Current Work \\
\hline
\end{tabular}

وتبين من خلال النتائج مما يلي:

ل إن طريقة Leier وآخرون لم يتطرقوا إلى أي ميزة من المميزات السابقة ماعدا ميزة تحليل القوة والتي تستتد إلى مفتاح خاص والتي هي عبارة عن سلسلة قصيرة من سلسلة DNA والتي تسمى بالبادئ (Primer) وهيئة إرسال السلسلة تكون كسلسلة DNA ولم يفصل كيفية إرسالها. ل إن طريقة Shimanaisky وآخرون تتضمن الإخفاء ضمن mRNA وتطرقوا إلى هيئة الإرسال بتحويل سلسلة DNA إلى أرقام حقيقة من خلال معاملة خاصة لسلسلة DNA ـ

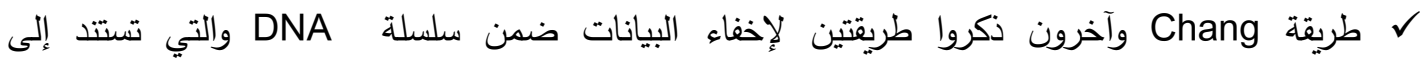
Software view عن طريقتا المقاسة بـ ( npc)، أما هيئة إرسال فكانت عبارة عن سلسلة DNA مكبوسة.

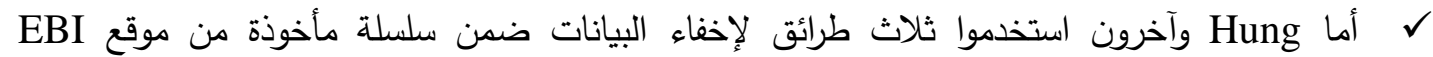
وتطرقوا إلى تحليل القوة والسعة وهيئة الإرسال. تم الاعتماد في دراستتا الحالية على المقاييس التي استخدمها Hung للمقارنة لكونها الأحدث والأفضل من الطرائق السابقة، فكانت تطبيق الطريقة المقترحة من تحليل قوة وتحليل سعة أفضل من الطرائق السابقة.

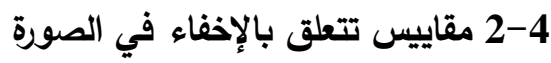

بعد إتمام إخفاء الرسالة في سلسلة DNA يتم إرسالها إلى الطرف ضمن إحدى الوساء في الوسائط المتعددة، في هذا

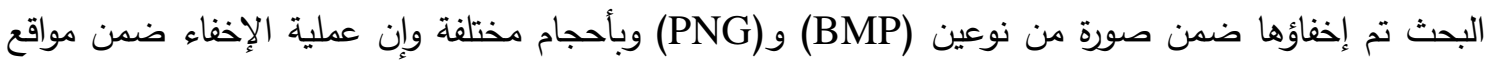

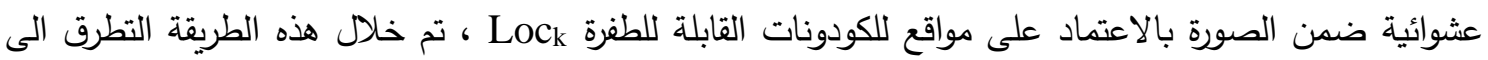

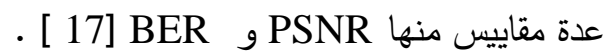
أ- مقياس نسبة ذروة الإشارة إلى الضوضاء ويحسب MSE من خلال المعادلة الآتية:

$$
\begin{gathered}
P S N R=10 \log _{10}\left(\frac{C_{\max }^{2}}{M S E}\right) \text { in } d B \\
M S E=\frac{1}{M N} \sum_{x=1}^{M} \sum_{y=1}^{N}\left(S_{x y}-C_{x y}\right)^{2}
\end{gathered}
$$

علما أن M, N: تمثلان أبعاد الصورة تمثلان الصورة الأصلية والغطاء Stego-image S $_{\text {xy }}, C_{x y}$ 
C C أعلى قيمة لونية في الصورة تساوي 255 [18ax

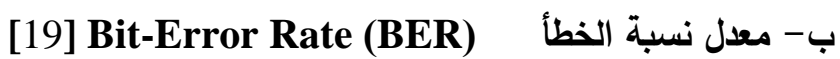
BER $=$ Error extracted bit $/$ Total embedded bit $\times 100$ فكانت نتائج تضمين السلسلة Snew ضمن صورة ملونة من نوع PNG كما هو مبين بالجدول(6) في حالة استخدام سلسلة طولها 4038 قاعدة.

الجدول (6). نتائج إخفاء سلسلة SNA

\begin{tabular}{|c|c|c|c|c|c|c|c|}
\hline BER\% & $\begin{array}{l}\text { PSNR } \\
\text { in } \mathrm{db}\end{array}$ & $\begin{array}{l}\text { صورة } \\
\text { Stego- }\end{array}$ & $\begin{array}{c}\text { طول سلسلة } \\
\text { DNA (Byte) }\end{array}$ & حجم الصورة & أبعاد الصورة & الأصلية الصورة & $ت$ \\
\hline 0 & 60.58 & $324 \mathrm{~KB}$ & 4038 & $379 \mathrm{~KB}$ & $500 \times 376$ & Chin & 1 \\
\hline 0 & 60.08 & $287 \mathrm{~KB}$ & $=$ & $373 \mathrm{~KB}$ & $500 \times 333$ & Person & 2 \\
\hline 0 & 60.29 & $198 \mathrm{~KB}$ & $=$ & $228 \mathrm{~KB}$ & $600 \times 300$ & Photo & 3 \\
\hline 0 & 62.04 & $568 \mathrm{~KB}$ & $=$ & $630 \mathrm{~KB}$ & $512 \times 512$ & Motor & 4 \\
\hline 0 & 59.90 & $318 \mathrm{~KB}$ & $=$ & $391 \mathrm{~KB}$ & $400 \times 400$ & Ghouse & 5 \\
\hline
\end{tabular}

ومن ملاحظة الجداول (6)

• تم احتساب قيمة PSNR بين الصورة الغطاء والصورة stego-image جيدة وحققت بذلك نسبة عالية في عدم القدرة على تمييز الغطاء عن stego-image أو بمعنى آخر عدم القدرة على الاكتثاف.

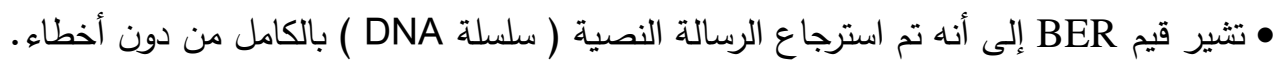
ويعرض الثكل (12) نموذجا لصورة ذات امتداد PNG من صور الاختبار .

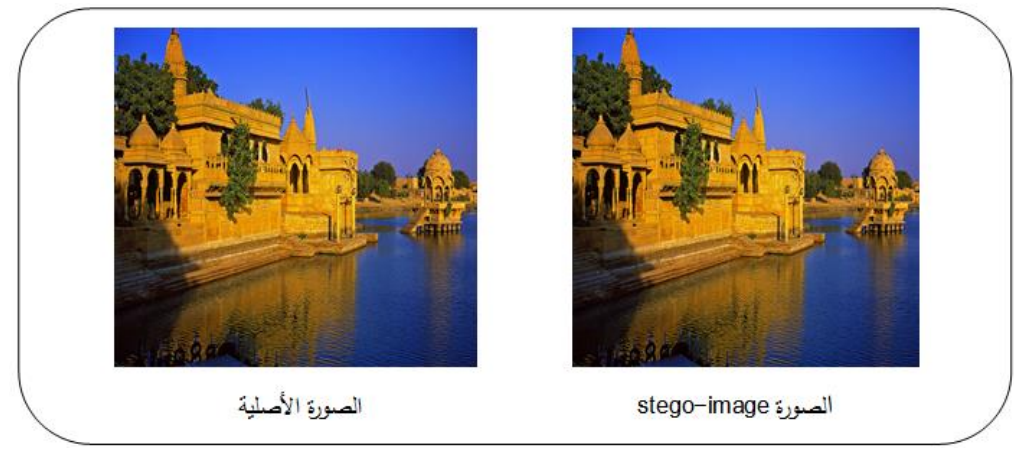

(Ghouse.png) طولها 4038 قاعدة في الصورة DNA (12). إخفاء سلسلة

فكانت نتائج تضمين السلسلة Snew ضمن صورة ملونة من نوع BMP كما هو مبين بالجدول(7) في حالة استخدام سلسلة طولها 4038 قاعدة.

الجدول (7). نتائج إخفاء سلسلة SNA DNA في صور ملونة ذات امتدادBMP

\begin{tabular}{|c|c|c|c|c|c|c|c|}
\hline $\begin{array}{c}\text { BER } \\
\%\end{array}$ & $\begin{array}{l}\text { PSNR } \\
\text { in dB }\end{array}$ & $\begin{array}{c}\text { صورة } \\
\text { Stego-image }\end{array}$ & طول سلسلة & الصوزة & $\begin{array}{c}\text { أبعاد الصلورة } \\
\text { الأصلية } \\
\text { Pixel }\end{array}$ & $\begin{array}{c}\text { الصورة الأصلية } \\
\text { Ck }\end{array}$ & 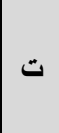 \\
\hline 0 & 62.07 & $768 \mathrm{~KB}$ & 4038 & $768 \mathrm{~KB}$ & $512 \times 512$ & Football & 1 \\
\hline 0 & 62.20 & $197 \mathrm{~KB}$ & $=$ & $197 \mathrm{~KB}$ & $800 \times 450$ & Cartoon & 2 \\
\hline 0 & 61.64 & $704 \mathrm{~KB}$ & $=$ & $704 \mathrm{~KB}$ & $600 \times 401$ & House & 3 \\
\hline 0 & 63.88 & $1.41 \mathrm{MB}$ & $=$ & $1.41 \mathrm{MB}$ & $800 \times 500$ & City & 4 \\
\hline 0 & 60.25 & $468 \mathrm{~KB}$ & $=$ & $468 \mathrm{~KB}$ & $400 \times 400$ & Fly & 5 \\
\hline
\end{tabular}




$$
\text { ومن ملاحظة الجداول (7) يتبين الآتي: }
$$

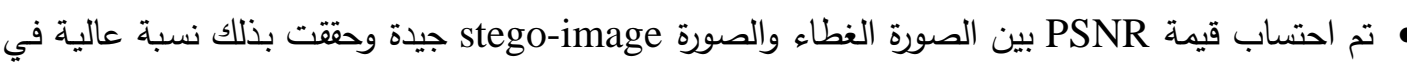
عدم القدرة على تمييز الغطاء عن stego-image أو بمعنى آخر عدم القدرة على الاكتشاف. • تثير قيم BER إلى أنه تم استرجاع الرسالة ( سلسلة SNA DNo ويعرض الثكل (13) نموذجا لصورة ذات امتداد BMP من صور الاختبار .

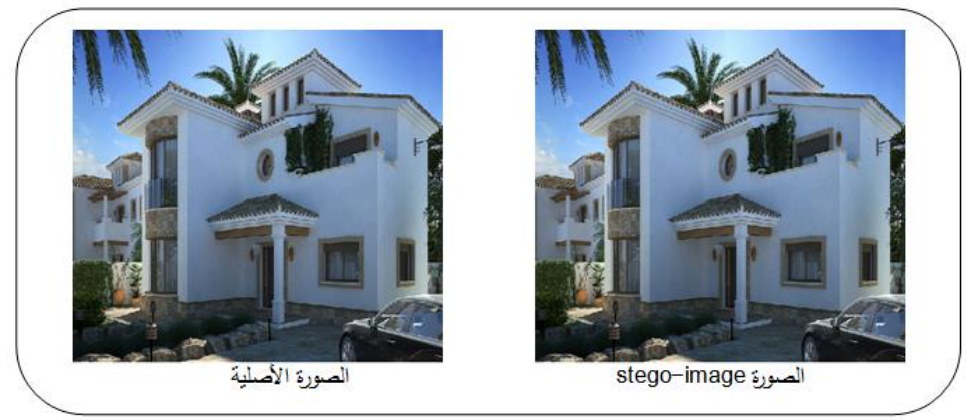

الثكل (13). إخفاء سلسلة DNA طولها 4038 قاعدة في الصورة (House.bmp)

جدول (8). ملخص النتائج من تطبيق إخفاء سلسلة DNA طولها 4038 قاعدة في الصورة

\begin{tabular}{|c|c|c|c|c|c|c|}
\hline زمن الاستخلاص & $\begin{array}{c}\text { زالإخفاء } \\
\text { (sec) }\end{array}$ & BER \% & PSNR in Db & أبعاد الصورة (pixel) & الأصلية & الصورة الصتاد \\
\hline 3 & 3 & 0 & 62.04 & $512 \times 512$ & Motor & PNG \\
\hline 3 & 3 & 0 & 62.07 & $512 \times 512$ & Football & BMP \\
\hline 3 & 3 & 0 & 60.29 & $600 \times 300$ & Photo & PNG \\
\hline 3 & 3 & 0 & 61.64 & $600 \times 401$ & House & BMP \\
\hline 3 & 3 & 0 & 59.90 & $400 \times 400$ & Ghouse & PNG \\
\hline 3 & 3 & 0 & 60.25 & $400 \times 400$ & Fly & BMP \\
\hline
\end{tabular}

يمكن تلخيص ما تم الحصول عليه من نتائج في الجداول السابقة بالجدول (8) أجريت التجارب باستخدام نظام حاسوبي من نوع Pentium4 بمواصفات (RAM =2GB CPU = 2.13GHz)

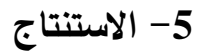

1- تعد سلسلة DNA وسطاً جيد جداً لإخفاء الرسالة السرية. 2- من البديهيات أن العمل مع سلسلة DNA يتطلب معرفة كاملة وخلفية نظرية في البايولوجي الجزيئي. 3- من الصعوبة كثف المحلل لسلسلةDNA الحاملة للرسالة السرية والمتفق عليها بين الطرفين والمأخوذة من قاعدة البيانات EBI بسرعة لانها تحتوي على مايقارب من 163 مليون سلسلة DNA لكائنات مختلفة. 4- من نقاط القوة للطريقة الجديدة هو ثبوت طول سلسلة الـ DNA وأثكالها وترتيبها قبل وبعد الإخفاء. 5- بالإمكان نقل سلسلة DNA الحاملة للرسالة السرية ضمن وسط من الوسائط المتعددة مما أعطى أمنية أعلى للطريقة.

6- تم اعتماد مواقع الكودونات (نفسها) نقاطاً عشوائية لغرض الإخفاء مما أضافة درجة أمنية أعلى للطريقة. 7- بالإمكان نقل سلسلة DNA الحاملة للرسالة السرية بالطريقة البيولوجية أو الحاسوبية. 
8 - إن العمل على سلسلة DNA حقيقي النواة (الإنسان) تحتاج إلى جهد أكثر من العمل على سلسلة DNA

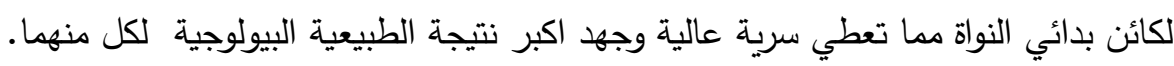




\section{المصادر}

[1] Al-Husainy M.A.F., (2009), "Image Steganography by Mapping Pixels to Letters", J. Computer Sci., Vol. 5, No. 1, pp.33-38.

[2] Prasad M. S. and etal., (2009), "A Novel Information Hiding Technique For Security By Using Image Steganography", Journal of Theoretical and Applied Information Technology, Vol. 8, No. 1, pp.35-39.

[3] Motameni H. and etal, (2007), "Labeling Method in Steganography", World Acad. Sci. Eng. Technol., Issue 30, pp. 349-354.

[4] B. Shimanovskg, J. feng, M. potkonjak, (2002), "Data Hiding in DNA", international workshop on information Hiding, pp. (373-386).

[5] Du W. C. and Hsu W. J., (2003), "Adaptive Data Hiding Based on VQ Compressed Images", IEE Proc.-Vis. Image Signal Process., Vol. 150, No. 4, pp. 233-238.

[6] Rocha A., and Goldenstein S.,(2008), "Steganography and Steganalysis in Digital Multimedia: Hype or Hallelujah?", RITA,Vol. 15, No. 1, pp.83-110.

[7] Bharti V., and Snigdh I., (2008), "Practical Development and Deployment of Covert Communication in IPV4", Journal of Theoretical and Applied Information Technology, Vol. 4, No. 6, pp.466-437.

القاري، سمير حسن، (2007)، "محاضرة الثانية في مادة الخلية والوارثة، جامعة الزرقاء، الأردن.

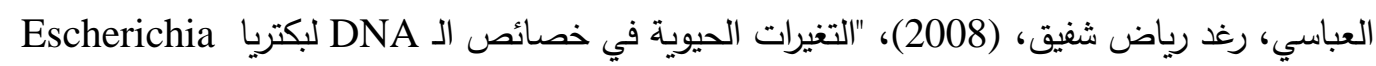

coli بعد تكسيره واستخدامه في الكلونة"، بحث ماجستير، قسم علوم الحياة، كلية العلوم، جامعة الموصل،

$$
\text { العراق. }
$$

[10] http://www.ebi.ac.uk, (2011),European Bioinformatics Institute.

$$
\text { البكري، غالب حمزة، 1991، مبادئ الهندسة الوراثية، كلية العلوم، جامعة البصرة، العراق. }
$$

[12] Dominik H. and Angelika . B, (2007), "DNA-based watermarks using the DNA cryptoalgorithm" , BMC Bioinformatics . VOL . 8, Germany

[13] Lee. CH. Hung, and et al., (2010), "Data Hiding Methods based upon DNA sequence", information Sciences, pp.(2196-2208), Journal homepage. www.elsvier.com Locate / ins, Taiwan .

الخفاجي، زهرة محمود، (2008)، التقنية الحيوية الميكروبية (توجيهات جزيئية) جامعة بغداد، العراق.

[15] Felix. B., (2006), "on the Embedding Capacity of DNA strands under substitution and Deletion Mutations", school of computer Science \& informatics, university, college Dublin , Belfield -Compus, Dublin, Ireland.

[16] A.Leier and etal , (2000), "Cryptography with DNA binary Stands", Biosystems. V. 57, pp (13-22).

عبدالمجيد، أنسام أسامة،2011،"طريقة جديدة للكتابة المغطاة في الصور المكبوسة بالتكميم ألاتجاهي"،

$$
\text { رسالة ماجستير، علوم الحاسوب،كلية علوم الحاسوب والرياضيات،جامعة الموصل، العراق }
$$

[18] Cheddad and etal., (2010),"Digital Image Steganography: Survey and Analysis of Current Methods", Signal Processing, Vol.90, Issue 3, pp.727-752.

$$
\text { الوري، احمد سامي، (2006)، "تقصي تغطية المعلومات في الصور ألمتحركة"، رسالة دكتوراه، علوم }
$$

